\title{
Effective Fair Pricing of International Mutual Funds
}

\author{
Choong Tze Chua \\ Singapore Management University \\ Sandy S. Lai \\ Singapore Management University \\ Yangru $\mathrm{Wu}^{*}$ \\ Rutgers University \\ and \\ Singapore Management University
}

April 5, 2005

\begin{abstract}
We propose a new methodology to provide fair prices of international mutual funds by adjusting prices at the individual securities level using a comprehensive information set. Stepwise regressions are used to endogenously determine the stock-specific optimal set of instruments in estimating the fair price of each stock in a fund. We compare the performance of our approach with existing ones using 16 U.S.-based Japanese funds. Our method predicts significantly more accurately fund prices at next-day Japan open, which are the best proxies for the unobserved prices at U.S. close. The existing methods are shown to be highly vulnerable to speculative attacks while our method is the most successful in preventing such strategic exploitation in that no competing method can profit significantly from our stated price. Our method can profit from the existing methods significantly by between 23 to 80 percent annually. Simulation results show that our method is superior to existing ones regardless of the style of the funds, such as different turnover ratios, stock sizes, number of stocks in a fund, and book-to-market ratios.
\end{abstract}

Key Words: Stale pricing, Fair pricing, International mutual funds, Stepwise regression JEL Codes: G10, G21, G15

\footnotetext{
* Choong Tze Chua is from Lee Kong Chian School of Business, Singapore Management University, 469 Bukit Timah Road, Singapore 259756, tel: (65) 6822-0745, fax: (65) 6822-0777, ctchua@smu.edu.sg; Sandy Lai is from Lee Kong Chian School of Business, Singapore Management University, 469 Bukit Timah Road, Singapore 259756, tel: (65) 6822-0738, fax: (65) 6822-0777, sandylai@smu.edu.sg; Yangru Wu is from Rutgers Business SchoolNewark \& New Brunswick, Rutgers University, Newark, NJ 07922, tel: (973) 353-1146, Fax: (973) 353-1233, yangruwu@andromeda.rutgers.edu, and is currently visiting Lee Kong Chian School of Business, Singapore Management University. We are grateful to the Office for Research of Singapore Management University for financial support.
} 


\section{Introduction}

Over the past two decades, with international financial markets becoming more and more integrated, the extent of cross-border investments has been steadily increasing. One convenient instrument for cross-border investing is international mutual funds because they offer international diversification benefits and professional management at reasonably low costs. To provide daily liquidity to investors, an international mutual fund allows investors to buy and sell shares of the fund at its net asset value (NAV), which is typically estimated by the daily foreign market close prices of the constituent foreign stocks of the fund. If the U.S. trading hours do not coincide with the foreign trading hours, the NAV estimated by the so-called stale prices of the stocks will not reflect the true value of the fund at the U.S. market close. Consider a U.S.-based fund investing solely in Japanese stocks traded at the Tokyo Stock Exchange which closes at 1am EST. At 4pm EST when the U.S. market closes, the previous Japan close prices of the stocks that are to be used to estimate the NAV of the fund will be 15 hours old. An investor can use the new information that arrived between Japan close and U.S. close to guide his buy/sell decisions. For example, suppose that positive news about the Japanese stocks is released after Japan close and before U.S. close, an investor can buy the fund at its NAV which is determined by the Japan close prices of the stocks, and expect the asset prices to go up the next day to make a profit.

The issue that stale pricing can be subject to serious speculative attacks has been discussed by previous researchers. See Bhargava et al. (1998), Boudoukh et al. (2002), Chalmers et al. (2001), Goetzmann et al. (2001), Greene and Hodges (2002), and Zitzewitz (2003). The issue has recently captured much regulatory attention. For example, on April 13, 2004, the SEC voted to adopt disclosure requirements for mutual funds to explain in their prospectuses both the circumstances under which they will use fair value pricing and the effects of using fair value pricing. The SEC originally proposed to impose a mandatory two percent fee on investors who 
take money out of a fund within five days, but had to recently shelve the proposal due to opposition from investors. ${ }^{1}$ The mutual fund industry indeed has various policies in place to curb daily speculation, such as front-end loads, redemption fees, transaction fees, and transaction restrictions. However, loads and redemption fees are in general not welcomed by investors. Furthermore, even though fees may attenuate the speculative profitability for an individual market timer, but they cannot resolve the stale pricing problem at the fund level. So long as funds use the wrong price, there is room for market timers to exploit the passive (or buy-andhold) investors. Furthermore, fees will necessarily create economic distortions because they impose costs on all investors, not just those attempting to exploit pricing errors. Transaction restrictions, while not imposing an explicit cost to investors, can already create a deadweight loss due to the loss in liquidity. To prevent market timing, a fund may also require purchase and redemption on the basis of the next-day NAV. However, this method creates additional price uncertainty in investors' decision making and is therefore not welcomed.

Perhaps a better way to resolve mutual fund pricing problem is to obtain a good estimate of the unobserved true NAV at the time of trading, and use the estimated price (the so-called fair price) for actual transactions. ${ }^{2}$ Goetzmann et al. (2001) suggests setting the NAV of a fund using market-wide available information up to the time of the exchange in fund shares. In their empirical work, they use the S\&P500 index returns at U.S. close to adjust the NAV of the funds.

This paper suggests a new method to estimate fair prices of U.S.-based mutual funds investing in international stocks by adjusting prices at the individual securities level using stepwise regression. Our work is built upon Goetzmann et al. (2001), but has several significant

\footnotetext{
${ }^{1}$ For detailed information, see the article in http://www.sec.gov/news/press/2004-50.htm and the WSJ article 'Mutual-fund timers get clocked' on August 23, 2004.

${ }^{2}$ Boudoukh et al. (2002) points out that any estimation of fair price will create model risk and estimation uncertainty and to the extent that an updating procedure becomes known, speculators may be able to exploit the estimation errors. Therefore, how well an estimation method works in practice is an empirical question.
} 
extensions. By adjusting prices at the individual securities level, our method can incorporate the effects of dynamic factor loadings due to portfolio turnover. In addition to market-wide information which is employed by Goetzmann et al. to adjust fund prices, inspired by the literature on cross-border linkage of security returns we employ a comprehensive set of relevant information available at U.S. close to estimate the fair prices of the constituent foreign stocks in a fund. ${ }^{3}$ To use information efficiently, we employ a simplified version of stepwise regression to endogenously determine the parsimonious security-specific optimal set of instruments to be included in estimating the price of each stock under investigation. Since the information set we consider is rather broad, it will not be feasible to utilize this information set in a parsimonious regression at the portfolio level. Finally, we also improve upon the design of our regression to estimate fair prices. Goetzmann et al. use as their dependent variable the percentage change in a fund's NAV in dollar terms at U.S. close (which reflects the stale price in foreign currency terms at foreign market close and exchange rate at U.S. close), whereas we use security return in dollar terms from previous-day foreign close to foreign open as the dependent variable in our regression. Our design shortens the irrelevant interval covered by the dependent variable, thereby avoiding introducing additional noise into our regression. The reduction in noise relative to signal allows us to estimate our regression parameters more efficiently.

We compare the performance of our method which estimates fair prices at the individual securities level with Goetzmann et al. (2001) that adjusts prices at the portfolio level using 16 U.S.-based mutual funds investing exclusively in Japanese stocks. We find that our approach

\footnotetext{
${ }^{3}$ Chalmers et al. (2001) estimate the fair price of a small-cap domestic fund. The stale pricing problem arises due to intra-market non-synchronous trading (mostly for small-cap stocks). Greene and Hodges (2002), however, demonstrate that there is little evidence of daily fund flows consistent with strategic trading in domestic funds and that there is little evidence of dilution impact. This paper deals with stale pricing for international funds due to intermarket non-synchronous trading. Apparently, there exists also intra-market non-synchronous trading in the foreign market and this can magnify the stale pricing problem induced by inter-market non-synchronous trading for international funds. However, this paper does not address the former issue because we do not have detailed data on last trading of foreign stocks. Furthermore, the inter-market induced stale pricing problem is obviously much more serious than that induced by non-synchronous trading in the foreign market in our context.
} 
yields significantly lower root mean square errors (RMSE) in predicting fund prices at the nextday Japan open, which are the best proxies for the unobserved prices at U.S. close, than the alternative regardless of the choice of market indexes used in the latter approach. While both methods remove much of return predictability of stale prices, the fair prices adjusted at the portfolio level remains highly vulnerable to speculative attacks. In contrast, our fair prices obtained at the individual securities level are not significantly exploitable. Furthermore, given any other estimated fair price from the existing approach, our method can profit from it significantly, and our method is also more successful than other competing methods in profitably exploiting the candidate fair price.

The remainder of the paper is organized as follows. Section I describes the existing methods as well as our method of estimating fair prices of international mutual funds. Section II explains the information set employed in our empirical analysis and describes the data. The design of experiment is presented in Section III. Empirical results for 16 U.S.-based Japanese mutual funds are reported in Section IV. Section V conducts a number of simulations to check for robustness of our results and the final section concludes the paper.

\section{Extant vs. Proposed Fair-Pricing Approaches}

Recent studies by Bhargava el al. (1998), Bhargava and Dubofsky (2001), Chalmers et al. (2001), Goetzmann et al. (2001), Greene and Hodges (2002), and Zitzewitz (2003) point out that a simple trading rule using the S\&P500 index returns as the signal to trade on international mutual funds can generate substantial profits. Given the overwhelming evidence on national stock market comovement, it is not surprising that returns on the S\&P500 index can predict the 
over-night returns on foreign securities and as a result, a simple trading rule using the former to infer the latter turns out to be considerably profitable. ${ }^{4}$

We present the estimation methods in the context of pricing a Japanese fund, although they can be similarly applied to multi-country funds. The following equation is employed by Goetzmann et al. (2001) to estimate the fair price of U.S.-based international fund shares:

$$
R_{K, t}=\alpha_{K}+\sum_{M} \beta_{K}^{M} R_{M, t-1}+\mu_{K, t}
$$

where $R_{K, t}$ refers to the percentage change in fund K's unadjusted NAV in dollar terms measured at U.S. close from day (t-1) to day t. Because the unadjusted NAV is computed using stale prices, $R_{K, t}$ in fact compounds the return in yen terms of Japanese stocks from Japan close on day (t-1) to Japan close on day $t$ and the return in the yen exchange rate from U.S. close on day (t-1) to U.S. close on day t. This relationship is shown below:

$$
\begin{aligned}
1+R_{K, t} & =\left[\frac{P_{K, t}^{\text {stock }}}{P_{K, t-1}^{\text {stock }}}\right]\left[\frac{S_{t}}{S_{t-1}}\right] \\
& =\left(1+R_{K, t}^{\text {stock }}\right)\left(1+R_{t}^{F X}\right)
\end{aligned}
$$

where $P_{K, t}^{\text {stock }}$ is the value of the underlying stocks (or NAV of the fund) in yen terms at Japan close on day t, $R_{K, t}^{\text {stock }}$ is the return of the stocks, $S_{t}$ is the dollar price of the Japanese yen at U.S. close on day $\mathrm{t}$ and $R_{t}^{F X}$ is the percentage appreciation of the yen. See Figure I Panel A for the exact timing of these variables.

On the right hand side of regression (1), $R_{M, t-1}$ denotes the return on index M from U.S. close on day (t-2) to U.S. close on day (t-1), where M can be the S\&P500 index and/or other

\footnotetext{
${ }^{4}$ Hilliard (1979) reports intra-continental stock markets comovement. Eun and Shim (1989) examine international comovement across Asian, European, and North American markets and show that the U.S. market movements are quickly transmitted to other markets. The comovement pattern between the U.S. and Japanese markets in particular is documented by Becker et al. (1990), Hamao et al. (1990), and Karolyi and Stulz (1996).
} 
market-wide information such as the Nikkei225 or the Japan exchange traded fund (ETF) index, $\alpha_{K}$ and $\beta_{K}^{M}$ are regression coefficients, and $\mu_{K, t}$ is the error term. Once the regression coefficients are estimated using information available at U.S. close on day t, the fund's NAV on day t can be adjusted by multiplying the unadjusted NAV available at U.S. close on day t (which is computed using stale stock prices at Japan close on day t) by $\left(1+\sum_{M} \hat{\beta}_{K}^{M} R_{M, t}\right)$, while ignoring the $\alpha_{K}$ as it is empirically small and insignificant. In their empirical work, Goetzmann et al. use the S\&P500 index return as the single explanatory variable to adjust a fund's daily share price.

Although the above approach is shown to be able to reduce much return predictability in international funds, two problems can emerge. Firstly, as asset price is adjusted at the fund level, this approach may fail to incorporate the effects of dynamic factor loadings due to portfolio turnover. Secondly, since only market-wide information (e.g. the S\&P500 and ETF indices) is employed to adjust the NAV of a fund, the above approach potentially ignores valuable information that may help determine the fair prices of the constituent stocks in the fund. Failure to account for valuable information can result in the estimated fair prices vulnerable to exploitation if a sophisticated speculator can design a more efficient estimation strategy to make better use of the information.

Inspired by the literature on cross-border linkage of security returns, we propose a new approach to overcome the above problems. The international asset pricing literature suggests that in addition to the U.S. market portfolio, other factors such as the Japanese market portfolio, industry portfolios, foreign exchange rate, distress and momentum factors, can also have explanatory power for the returns of Japanese securities. These factors affect individual security prices differently depending on aspects such as the accessibility of the particular Japanese security to U.S. investors, the security's currency exposures, etc. Hence, adjusting asset prices at 
the securities level may better reduce the return predictability in U.S.-based Japanese funds. We propose to estimate the concurrent yet unobservable prices of Japanese securities at the U.S. close using the following regression model:

$$
r_{i, t}=\alpha_{i}+\sum_{F} \beta_{i}^{F} R_{F, t-1}+\mu_{i, t}
$$

where the lower case $r_{i, t}$ refers to the return in dollar terms on Japanese stock i from Japan close on day (t-1) to Japan open on day t, F refers to the factors that we use to estimate the returns on Japanese securities, and $R_{F, t-1}$ are the returns of those factors from U.S. close on day (t-2) to U.S. close on day (t-1). The factors are all observable at U.S. close and hence make up our base information set for predicting Japanese securities returns. Once the regression coefficients are estimated, security i's price at U.S. close on day t is then estimated as its unadjusted dollar price measured at Japan close on date t multiplied by $\left(1+\sum_{F} \hat{\beta}_{i}^{F} R_{F, t}\right)$, while ignoring the $\alpha_{i}$ following Goetzmann et al. A fund's price can then be calculated as the value-weighted average price of its constituent stocks.

To trade off information vs. noise embedded in those pricing factors, in our empirical estimation we employ a version of stepwise regression to endogenously select only those pricing factors that are significant at the one percent level for each security. We implement the forward selection procedure under which we start with the intercept. Variables are then added one at a time, where the variable that gives the highest partial $F$-statistic at each step is chosen. The choice of variables is finalized when the next best variable is not significant at the predetermined one percent significance level (see Draper and Smith (1998, pp. 335-344) for more information 
of stepwise regression and the forward selection procedure). All regressions are estimated by OLS. ${ }^{5}$

Our methodology also improves upon the regression design. As illustrated in Figure I, the dependent variable in Goetzmann et al., $R_{K, t}$, which is the compounded return on the underlying stocks (in yen terms) and exchange rate, covers the period from Japan close on day (t-1) to U.S. close on day t, while our dependent variable, $r_{i, t}$, covers the period from Japan close on day (t-1) to Japan open on day t. Since the return from Japan open to U.S. close on day t is unforecastable by the explanatory variables at U.S. close on day (t-1), this setup of our dependent variable avoids introducing additional noise into our regression. This design increases the signal to noise ratio in our regression relative to Goetzmann et al., thereby resulting in more efficient estimation of regression parameters.

\section{Relevant Information Set, Data and Sample Statistics}

In this section, we discuss the information set used to estimate the over-night returns of Japanese securities and describe the data and sample statistics.

\section{A. Relevant Information Set}

\section{$\underline{\text { U.S. and Japanese Market Portfolios }}$}

Goetzmann et al. show that the S\&P500 index has predictive power over the next-day Japanese fund share prices. Since the Nikkei225 futures contracts are traded on the Chicago Mercantile Exchange and their returns are observable during U.S. trading hours, it is thus interesting to ask whether the Nikkei225 will have additional predictive power over and above

\footnotetext{
${ }^{5}$ Burns et al. (1998) propose an asynchronous GARCH model to estimate returns and volatilities of foreign indices at U.S. close. Since our focus is on returns rather than volatilities, other than the heavy computational burden, there is no obvious added benefit from using GARCH rather than OLS regression.
} 
the S\&P500 for returns on Japanese securities. According to international capital asset pricing theory, if the Japanese market is segmented from the world market, the Nikkei225 should be the only pricing factor for Japanese securities. On the other hand, if the Japanese market is fully or partially integrated with the world, the S\&P500 and Nikkei225 should have their own distinctive predictive power on the over-night returns of Japanese securities. ${ }^{6}$ Results from Campbell and Hamao (1992) suggest that the U.S. and Japanese markets are at least partially integrated. In addition to the Nikkei225, we also consider the Japan ETF (iShares) and the equally-weighted Japanese ADR index as alternative proxies for the Japanese market portfolio.

\section{Size, Book-to-market, and Momentum Factors}

The empirical four-factor asset pricing model has been widely used to characterize security returns since the landmark work by Fama and French (1996) and Carhart (1997). ${ }^{7}$ On the international front, Fama and French (1998) show that value-growth returns are positively correlated across countries and that the international two-factor model with the global market and distress as factors is superior to the international CAPM in explaining the global value premium. Jegadeesh and Titman (1993) document the profitability of momentum trading strategies. Rouwenhorst (1998) examines international momentum effects and finds that international momentum returns are correlated with those of the U.S. He argues that exposure to a common global factor may drive the profitability of momentum strategies. If global component is indeed present in size, book-to-market and momentum factors, U.S. factors should be

\footnotetext{
${ }^{6}$ Errunza and Losq (1985) and Eun and Janakiramanan (1986) show that under complete market integration, the expected return of a Japanese security should depend on its covariance with the world portfolio. Under partial market integration, Japanese securities which are available to investors without any ownership constraint would be priced as if markets were fully integrated, whereas those available to only domestic Japanese investors or those with an ownership constraint would be priced according to their world beta and country beta.

${ }^{7}$ Chan et al. (1991) show that size and book-to-market ratio also provide a powerful characterization of the crosssectional differences in Japanese stocks returns.
} 
considered as relevant pricing factors for Japanese securities. We therefore include the U.S. size, book-to-market and momentum factors in our information set.

\section{Foreign Exchange Rate}

Motivated by previous literature, we include the daily change in the Japanese yen exchange rate in our regression. Jorion (1990) and Williamson (2001) show that changes in foreign exchange rates can affect firm values at various degrees depending on firms’ foreign exchange exposures. Dumas and Solnik (1995) document that foreign exchange risk is priced in equity returns of the world's four major equity markets. Using a panel of 171 Japanese multinational firms with substantial export to sales ratio, $\mathrm{He}$ and $\mathrm{Ng}$ (1998) document economically significant exposures in one quarter of the firms and show that a depreciation (appreciation) in the value of the yen results in a positive (negative) impact on the value of these Japanese exporting firms.

\section{$\underline{\text { Industry Factors }}$}

While industry factors are found to account for only a relatively small proportion of the variance of national stock market returns, Griffin and Karolyi (1998) suggest that the importance of industry effects in stock returns vary across industries: firms that produce goods traded internationally are found to have stronger industry effects in their returns than those that produce non-traded goods. ${ }^{8}$ Beckers et al. (1996) show that industry factors have additional explanatory power for security returns beyond global market and country-specific effects. Since industry factors contain relevant pricing information on security returns, we include them in the information set.

\footnotetext{
${ }^{8}$ Heston and Rouwenhorst (1994) and Griffin and Karolyi (1998) show that country factors are substantially more important than industry factors in explaining the cross-country variations of stock market returns.
} 


\section{American Depository Receipts (ADRs)}

An ADR represents a claim on the shares of its underlying home country security. In theory, the price movements of the former should mimic those of the latter and should hence be the only relevant pricing factor for the latter. Studies by Froot and Dabora (1999) and Chan et al. (2003), however, find that a security's price is also affected by the investor sentiment of the country in which it is traded. ${ }^{9}$ As such, ADRs should not be regarded as the only relevant pricing factor for their underlying home country securities. Considering that ADRs may also contain pricing information for their closely related firms, we include all Japanese ADRs in our information set.

\section{B. Data Description and Sample Statistics}

We obtain daily close-to-close return, open and close prices, market capitalization, industry classification, and fiscal year-end book-to-market ratios of Japanese securities from the Pacific-Basin Capital Market database (PACAP), which covers all securities traded on the Tokyo Stock Exchange from January 1, 1975 to December 31, 2001. Since the unadjusted close-to-open returns are complicated by the effect of dividend payout and stock split that may have occurred between the close of the previous day to the open of any given day, we construct a time series of adjusted close-to-open returns for each stock, which are used throughout the paper wherever applicable. ${ }^{10}$ The daily settlement prices of the S\&P500 futures and Nikkei225 futures are from the Chicago Mercantile Exchange, where the former started trading on April 21, 1982 and the

\footnotetext{
${ }^{9}$ Froot and Dabora (1999) examine the price behavior of three pairs of 'Siamese-twin' company stocks. They show that a twin's relative price is positively correlated with the market in which it is traded relatively intensely. Chan $e t$ al. (2003) find that after the Jardine Group moved its trading location from Hong Kong to Singapore in 1994, its stock price becomes more (less) correlated with the Singapore (Hong Kong) market.

${ }^{10}$ The adjusted close-to-open returns are calculated as the day's close-to-close returns (which are provided and are adjusted for dividends and stock splits) minus the day's open-to-close returns.
} 
latter on September 25, 1990. The returns on the S\&P500 and Nikkei225 futures are calculated as the percentage price changes in the respective futures contracts nearest to maturity. Returns on Japan ETF and ADRs are from CRSP. The daily U.S. momentum factor and size and book-tomarket factors are from Jeffrey Busse’s and Kenneth French’s websites, respectively. The returns on the yen-dollar exchange rate are acquired from the foreign exchange data vendor Olsen Associate. The data on U.S. three-month T-bill rates are obtained from the website of the Federal Reserve Bank of St. Louis.

To define the size membership of Japanese securities, we adopt a similar approach to that in Fama and French (1996). Specifically, at the beginning of July each year, we sort all Japanese stocks in PACAP in descending order by their market-cap at the end of June. The top 30 percent are classified as large-cap stocks, the middle 40 percent as mid-cap, and the bottom 30 percent as small-cap. The book-to-market membership of Japanese securities is defined in a similar manner. To construct industry portfolios, we group CRSP stocks into industry portfolios in a way similar to that in Fama and French (1997). However, to make the number of industries manageable, instead of classifying firms into forty-eight industries, we use a twelve-industry classification. ${ }^{11}$ The size, book-to-market and industry groups are updated at the beginning of July each year based on data at the end of June. The daily portfolio returns are calculated from July 1 to June 30 of the following year. Our sample period spans over 11 years, from January 2, 1991 to December 31, 2001.

We obtain the portfolio composition and sample characteristics of the U.S.-based Japanese funds from Morningstar. There are 16 pure Japanese funds (excluding index funds) alive in the Morningstar database as of March 2004 when we start this research. Table I reports the sample statistics of these 16 funds. Several things are noteworthy. The majority of the funds

\footnotetext{
${ }^{11}$ The details of our industry classification and Japanese ADRs are provided in the Appendix.
} 
follow a "large-cap" style (10 out of 16) and "growth" style (9 out of 16). The number of stocks in a fund varies greatly across funds, ranging from 33 for the Japan Smaller Companies fund and Matthews Japan fund to 973 for the Dimensional Japan Small Company fund. The annual turnover ratio also varies substantially across funds, ranging from 39 percent for the Japan Smaller Companies fund to 797 percent for the JP Morgan Fleming Japan fund.

\section{Design of Experiment}

To evaluate the effectiveness of fair-pricing approaches, we design an experiment in which we compare the out-of-sample forecast accuracy and exploitability of competing fairpricing methods using simulated daily holdings of Japanese funds. The details of the experiment are discussed below.

\section{A. Simulation of Fund Holdings: Actual vs. Synthetic Fund}

Since during the sample period the SEC only requires mutual funds to disclose their portfolio holdings on a semi-annual basis, daily holding information is not available to the public and hence need to be simulated for the purpose of this project. ${ }^{12}$ We simulate the daily portfolio holdings of the sample Japanese funds based on the turnover ratio and stock characteristics of the actual holdings of the U.S.-based Japanese funds. As a start, we obtain the most recent portfolio composition and turnover ratio information of U.S.-based Japanese funds from Morningstar. We then match each fund's constituent stocks with the securities in PACAP. If a stock is not identifiable in PACAP, we replace it with one randomly selected from the PACAP database. With the turnover ratios and stock characteristics of the 16 actual Japanese funds, we can

\footnotetext{
${ }^{12}$ The SEC now requires all funds to report their portfolio holdings on a quarterly basis for periods ending on or after July 9, 2004. See http://www.sec.gov/rules/final/33-8393.htm.
} 
simulate their daily portfolio holdings. ${ }^{13}$ We assume that every stock has an equal probability of being replaced by another stock with the same size membership. The probability of a stock being replaced is set equal to a fund's daily turnover ratio. We conduct 400 simulations for each fund.

Furthermore, we simulate daily fund holdings for four sets of synthetic funds. We are interested to see whether our empirical results hold up across funds with different turnover ratios, number of securities in portfolio, stock size, and book-to-market ratio characteristics. Hence, we construct synthetic funds along these dimensions. To construct synthetic funds with varying turnover ratios, we assume that each fund holds 69 securities, which is the median number of securities held by the 16 actual funds, and that these 69 stocks are randomly drawn from the universe of all Japanese stocks in PACAP. We allow the annual turnover ratio to vary from 10 to 1,000 percent. To construct funds with varying number of constituent stocks, we assume that each fund has an annual turnover ratio of 92.5 percent, the median turnover ratio of the 16 actual funds. Again, these stocks are randomly drawn from the PACAP universe. We then construct the synthetic fund with the number of constituent stocks ranging from 25 to 500. The synthetic large-, mid-, and small-cap (high-, mid-, low- book-to-market ratio) funds are constructed by assuming that each fund has an annual turnover ratio of 92.5 percent and holds 69 stocks in their portfolio; then the securities for each fund are randomly drawn from its corresponding size (book-tomarket ratio) category. Except for the experiments on the book-to-market ratio characteristic, where we replace stocks with the ones having the same book-to-market ratio membership, we always replace stocks based on their size characteristics. We conduct 400 simulations for each fund.

\section{B. Performance Measures}

\footnotetext{
${ }^{13}$ We are able to identify 87 percent of the stocks, leaving 13 percent unidentifiable either due to the stocks not being traded on the exchanges covered by PACAP, or due to irreconcilable differences in naming conventions used by Morningstar and PACAP to identify companies.
} 
In comparing the effectiveness of fair-pricing methods, we look at three performance measures: (1) a method's out-of-sample forecast accuracy; (2) the exploitability of the method by alternative methods; and (3) the profitability of the method in exploiting other methods. It seems intuitive that a better method should be one that yields a more accurate out-of-sample forecast, one whose stated price is more successful in preventing exploitation by other methods, and one that can exploit more profit from the stated price of an alternative estimation method than other feasible alternative methods.

To calculate the out-of-sample forecast accuracy, we compare the share price forecasted by each fair-pricing method with the actual price of the fund measured at the next-day Japan open. ${ }^{14}$ Recall that our purpose is to provide the best estimates of the unobserved stock prices (and hence fund price) at U.S. close. Since the true prices of Japanese stocks (and hence fund prices) at U.S. close are unobserved, we use the next-day Japan open prices (which are the earliest observable prices in the future) as the best proxies and measure the performance of each method by how accurately the method predicts the prices at next-day Japan open. In an efficient market where one cannot use information available at U.S. close to forecast asset prices at nextday Japan open, this performance criterion gives us the same rankings of estimation methods as the ideal but yet infeasible criterion which measures how accurately one method estimates the (unobserved) prices at U.S. close. The out-of-sample prediction error is computed daily and the root mean squared error (RMSE) is calculated over the sample period as follows:

$$
\mathrm{RMSE}=\left[\frac{1}{\mathrm{~N}} \sum_{\mathrm{t}=\mathrm{D} 1}^{\mathrm{D} 2} \varepsilon_{Q, t}^{2}\right]^{1 / 2}
$$

where

\footnotetext{
${ }^{14}$ The actual share price of a fund is computed as the value-weighted average of the dollar price of the fund's constituent stocks.
} 


$$
\begin{aligned}
\varepsilon_{Q, t} & =\frac{\hat{p}_{\mathrm{Q} \mathrm{t}(\mathrm{US} \text { close })}-p_{t+1 \text { (Japan open })}}{p_{t+1 \text { (Japan open })}} \\
& =\frac{\hat{p}_{\mathrm{Q} \mathrm{t}(\text { US close })}-p_{t \text { (USclose })}}{p_{t+1 \text { (Japan open })}}+\frac{p_{\mathrm{t}(\text { US close })}-p_{t+1 \text { (Japan open })}}{p_{t+1 \text { (Japan open })}} \\
& \equiv \eta_{\mathrm{Q}, \mathrm{t}}+\xi_{t}
\end{aligned}
$$

In the above equations, $p_{t}$ is actual value of the fund, $\hat{p}_{Q, t}$ is predicted value of the fund, both in dollar terms, and $\varepsilon_{Q, t}$ is the percentage prediction error for method $\mathrm{Q}$ on day t, which can be viewed as comprising two components: (i) the error in predicting a fund's price at U.S. close, $\eta_{\mathrm{Q}, \mathrm{t}}$; and (ii) the error in predicting the fund's price changes from U.S. close to next-day Japan open, $\xi_{t}$. In an efficient market, $\xi_{t}$ should be unpredictable by any method and uncorrelated with $\eta_{\mathrm{Q}, \mathrm{t}}$. D1, D2, and $\mathrm{N}$ denote the starting, ending, and length of the forecasting period, respectively.

To conduct a formal statistical test for the relative forecast accuracy of two competing methods, $Q_{1}$ and $Q_{2}$, we form the difference of square forecast errors and construct the associated $t$-statistic as follows:

$$
\begin{aligned}
& d_{t}=\varepsilon_{Q_{1}, t}^{2}-\varepsilon_{Q_{2}, t}^{2} \\
& t_{d}=\frac{\mu_{d}}{\sigma_{d} / \sqrt{N}}
\end{aligned}
$$

where $\mu_{d}$ and $\sigma_{d}$ are the sample (time-series) mean and standard deviation of $d_{t}$, respectively.

It is in general a stringent requirement in forecasting exercises to use statistical significance as a criterion to evaluate competing forecasting methods. ${ }^{15}$ This is even more so in our current context because the $t_{d}$ defined in (7) underestimates the true $t$-statistic to judge the

\footnotetext{
${ }^{15}$ See Pesaran and Timmermann (1995) for evidence on forecasting stock returns, Killian and Taylor (2003) and Qi and Wu (2003) on forecasting exchange rates, Duffee (2002) on forecasting interest rates, and Fama and French (1987) and Hartzmark (1991) on forecasting commodity futures.
} 
relative genuine forecasting abilities of two competing methods. To see this, we decompose the difference of square forecast errors as follows:

$$
\begin{aligned}
d_{t} & =\varepsilon_{Q_{1}, t}^{2}-\varepsilon_{Q_{2}, t}^{2} \\
& =\left(\eta_{Q_{1}, t}+\xi_{t}\right)^{2}-\left(\eta_{Q_{2}, t}+\xi_{t}\right)^{2} \\
& =\left(\eta_{Q_{1}, t}^{2}-\eta_{Q_{2}, t}^{2}\right)+2 \xi_{t}\left(\eta_{Q_{2}, t}-\eta_{Q_{2}, t}\right) \\
& \equiv d_{1 t}+d_{2 t}
\end{aligned}
$$

Note that the first term on the right hand side of (8), $d_{1 t} \equiv\left(\eta_{Q_{1}, t}^{2}-\eta_{Q_{2}, t}^{2}\right)$, is the difference in the genuine estimation errors by two competing methods. Therefore, the true $t$-statistic to compare the relative performance of two competing methods should be

$$
t_{d_{1}}=\frac{\mu_{d_{1}}}{\sigma_{d_{1}} / \sqrt{N}}
$$

where $\mu_{d_{1}}$ and $\sigma_{d_{1}}$ are the sample mean and standard deviation of $d_{1 t}$. This statistic is not computable because we do not directly observe $\xi_{t}$. Since $\xi_{t}$ is uncorrelated with $\eta_{\mathrm{Q}_{1}, \mathrm{t}}$ and $\eta_{\mathrm{Q}_{2}, \mathrm{t}}$, the second term on the right hand side of (8), $d_{2 t}$, has mean zero, is uncorrelated with the first term $d_{1 t}$, and its variance increases with the variance of $\xi_{t}$. Therefore, we have $\mu_{d}=\mu_{d_{1}}$ and $\sigma_{d}>\sigma_{d_{1}}$, which implies that

$$
\left|t_{d}\right|<\left|t_{d_{1}}\right|
$$

The above argument demonstrates that the $t$-statistic $t_{d}$ defined in (7) that we will compute understates the true statistical significance of one estimation method against another.

To avoid data mining, we use an accumulative estimation window for our method, while allowing the competing methods to use their respective optimal windows. An optimal window is defined as the one which produces the lowest RMSE over the forecasting period averaged across the 16 funds. Since doing so is likely to work against our method, if we still find our method 
performing better than the competing methods, the superiority of our method will be more evident.

Lastly, we measure the exploitability of an estimation method by an alternative method by calculating the profit of a simple trading strategy: buy a fund's share when the stated price by an alternative method is higher than the price stated by the one method to be exploited, and avoid investing in the fund when the stated price by the alternative method is lower than or equal to the price stated by the one method to be exploited. As short selling mutual funds is in general not allowed, we assume that in the latter case the position is held in the U.S. three-month T-bill. For simplicity, we assume that there is no transaction cost and that the decision is made daily. Although the assumption of zero transaction cost may not be realistic, it is acceptable assumption in our study because we are comparing alternative pricing methods. As long as the assumption is applied uniformly across all methods, it will not bias the study in favor of any method. This experiment is similar to that of Goetzmann el al. (2001). The trading profit is calculated daily and averaged over the sample period. A method is exploitable by an alternative method if the profit of this trading strategy is significantly greater than a benchmark strategy. We consider two benchmark strategies: buy-and-hold the U.S. T-bill and buy-and-hold the mutual fund under investigation for the entire sample period. If our method is indeed better than the competing methods, we expect that it will be difficult for the alternative methods to exploit the stated price of our method and that our method could exploit more profit from the stated prices of alternative estimation methods than other feasible alternatives. Standard $t$ test is employed to test whether a trading profit is statistically different from zero.

\section{Empirical Results from 16 Japanese Mutual Funds}


Our out-of-sample forecasting exercise starts on January 6, 1993 and ends on December 31, 2001 for the 16 actual Japanese mutual funds. To implement our methodology, for each constituent stock in a fund on each day, we run a stepwise regression of Equation (2) using the instrumental variables introduced in Section II. Once the optimal set of factors is selected from the stepwise regression, we use the estimated parameters to adjust the stock price. The regression is rolled over daily with an accumulative window as a new observation becomes available.

Table II reports the mean return, standard deviation, and cross correlation of the factors included in our information set. The proportion of times these factors are selected in our stepwise regressions into our final regression model are also displayed. Although it is eye-catching that the dollar-yen exchange rate is selected most often (94 percent of the time), it should not come as a surprise given the way our regression equation is set up. ${ }^{16}$ It is interesting to note that the Nikkei225 and S\&P500 futures are selected 66.24 percent and 42.92 percent of the time, respectively, suggesting that both indices contain material information about the over-night returns of Japanese securities with the former somewhat more important. The Japan ETF is selected only 8.29 percent of the time, implying that the Nikkei225 futures index is a superior proxy for the Japanese market portfolio to the Japan ETF. ADRs, size, industry, book-to-market and momentum factors also help predict Japanese security returns. They are selected into the regression model $4.49,2.06,2.02,1.88$, and 1.78 percent of the time, respectively. The correlation structure suggests that these factors are only moderately correlated except for Nikkei225, Japan ETF and ADRs. However, in cases where one of the three Japanese indexes are chosen, it is highly unlikely that any of the other two would be chosen as well. Hence, the multi-collinearity problem is not a major concern in our empirical model.

\footnotetext{
${ }^{16}$ In our regression model, we use the percentage changes in the dollar price of a Japanese security from Japan close to the next-day Japan open as the dependent variable. In this setting, even if a security's yen price remains unchanged during the period, its regression coefficient on the dollar-yen rate would be close to unity and is likely to be highly significant. Hence, it is not surprising that the exchange rate is selected most often compared to other factors.
} 
The existing alternative estimation method adjusts asset prices at the fund level using Equation (1) with market-wide information. We explore seven sets of market-wide explanatory variables in this case: (1) the S\&P500 futures; (2) the Nikkei225 futures; (3) the S\&P500 futures plus Nikkei225 futures; (4) the Japan ETF; (5) the equally-weighted average ADR index; (6) the S\&P500 futures plus the Japan ETF; and (7) the S\&P500 futures plus the equally-weighted average ADR index. Goetzmann et al. (2001) use information set (1) in their empirical work. The Nikkei225, the Japan ETF and the equally-weighted average ADR index are each suggested in the literature to serve as a proxy for the Japanese market portfolio. Empirically though, we find that the Nikkei225 futures index always outperforms the Japan ETF and the equallyweighted average ADR index. Panel A of Figure II shows that the RMSE of predicting the nextday Japan open prices using the Nikkei225 index alone is always lower than that using either the Japan ETF or the ADR index, while Panel B demonstrates that the RMSE using the Nikkei225 plus the S\&P500 is superior to that using either alternative index plus the S\&P500. Since the Nikkei225 is clearly dominating, we use only this index to proxy for the Japanese market portfolio, and will only report competing results using information sets (1)-(3). ${ }^{17}$

Figure III displays the RMSE against the window size for each of the three competing methods. We find that the cumulative window produces the lowest RMSE for the methods using the S\&P500 and the Nikkei225 indices alone respectively, while the 360-day fixed moving window is the optimal window size for the method using both the S\&P500 and Nikkei225. These respective optimal window sizes are used in estimation.

\section{A. Root Mean Square Errors}

\footnotetext{
${ }^{17}$ The ETF data also have a shorter history (from March 19, 1996) than the other two indices. Figures IIA and IIB are based on the sample period where all three indices have observations.
} 
Table III reports the results of the RMSE of predicting fund prices at next-day Japan open based on information available at U.S. close (4pm EST) using our estimation method and three competing methods for the 16 U.S.-based Japanese mutual funds. For ease of comparison, the result from stale pricing is also reported, although no estimation is needed in this case. The upper panel reports the RMSE for each estimation method, while the lower panel displays the $t$ statistics for testing that our method produces a lower RMSE than the alternative methods. If the $t$-statistic is smaller than -1.96 , then our method is considered to have a significantly lower RMSE than the alternative method at the 5 percent level. On the other hand, if the $t$-statistic is larger than 1.96, our method is considered to be worse than the alternative method at the 5 percent significance level. From Equation (5), we know that $\xi_{t}$ is a noise term that is present for all methods, while $\eta_{\mathrm{Q}, \mathrm{t}}$ captures the specific genuine estimation error of method $\mathrm{Q}$. Therefore the presence of $\xi_{t}$ makes the percentage difference in RMSE across competing methods smaller than the true percentage reduction due to the genuine estimation error. Also, as demonstrated in Equation (10), the $t$-statistics underestimate the true statistical significance of the difference between our method and the competing methods. With this caveat, an insignificant $t$-statistic will not necessarily imply that our method does not perform better, but a significant $t$-statistic will clearly indicate the superiority of our method relative a competing method. Two observations can be made from Table III.

Firstly, across estimation approaches, we find that stale pricing yields the highest RMSE in predicting fund prices at next-day Japan open. Method 3 (the Nikkei225 futures index alone) produces the second highest RMSE, followed by Method 2 (the S\&P500 futures index alone), and Method 4 (the S\&P500 futures and Nikkei225 futures indices combined). Our approach with stock-specific predicting variables produces the lowest RMSE among all methods. This is true across all 16 funds. Averaging over the 16 funds, we find that the mean RMSE using stale 
pricing is 0.771 percent. This number reduces to 0.694 percent for Method 3, 0.677 percent for Method 2, 0.651 percent for Method 4, and 0.632 percent for our method.

Secondly, according to Panel B of Table III, across all 16 funds, our method produces a lower RMSE than stale pricing with the average $t$-statistic of -8.758 . While this is a markedly high statistic, it is not surprising given that stale price is a lousy predictor of next-day open price. Compared with other fair pricing estimation methods, our method beats Method 2 (the S\&P500 futures index alone) at the 1 percent significance level for all 16 funds, with an average $t$-statistic of -5.106; and beats Method 3 (the Nikkei225 futures index alone) at the 1 percent level across 16 funds, with an average $t$-statistic of -6.227 . While our method outperforms Method 4 (with the S\&P500 and Nikkei225 indices combined) by a smaller margin, it does so at the 1 percent significance level for 13 funds and at the 5 percent significance level for 2 additional funds. The average $t$-statistic over all 16 funds is -2.829 , which is significant at the 1 percent level.

\section{B. Exploitability}

Given a declared price by one estimation method, we investigate how likely and by how much an alternative estimation method can profit from this stated price. In principle, an ideal method should employ the most updated and most relevant information and should use the information most effectively to come up with accurate estimate of a stock price at U.S. close. A perfect estimate should yield the true (but yet unobserved) stock price at U.S. close such that no method can profit from the declared price in an efficient market. However, in reality since no estimation method is perfect, when a stated price from one method is different from the true price, an alternative method which uses information not fully incorporated in the stated price may be able to profit from the stated price even if this alternative method may not necessarily be a superior method in terms of forecast accuracy. Of course, the more accurate an alternative 
method is in estimating the true price, the more likely the method is going to profit from a stated price. Therefore, it seems natural to evaluate the various estimation methods based on two additional criteria: (1) a good method should be one whose stated price is successful in guarding exploitation by other methods; and (2) a good method should be one that can exploit more profit from a stated price of an alternative estimation method than other feasible alternative methods.

Table IV reports the results using the benchmark of holding the U.S. T-bill. Panel A displays the mean excess returns and the associated $t$-statistics that our method can be exploited by the other alternative methods. For an alternative method to profit significantly at the 5 percent level from our stated price, a positive $t$-statistic larger than 1.96 is required. As the $t$-statistics show, none of the alternative methods can significantly exploit our method even at the 10 percent level for any of the 16 funds. Most of the $t$-statistics are below unity. Not surprisingly, across the four alternative methods, Method 5 (stale price) is the weakest method in exploiting our stated price with the average $t$-statistic of 0.324 over 16 funds, whereas Method 4 (the S\&P500 plus Nikkei225 indices) is the strongest with the average $t$-statistic equal to 1.271. Method 2 (the S\&P500 index alone) performs somewhat better than Method 3 (the Nikkei225 index alone). These results, consistent with those on the comparison of out-of-sample RMSE's, imply that the S\&P500 index in general contains more (or better) information than the Nikkei225 index in pricing Japanese stocks. However, neither factor can entirely substitute for the other. Combining the two indices clearly improves estimation efficiency, but the improved estimate is insufficient to exploit profitably our method.

Organized in the same manner, Panel B of Table IV presents the excess profits and the associated $t$-statistics that Method 2 (the S\&P500 index alone) can be exploited by the other methods. The $t$-statistics indicate that Method 2 can be profited significantly at the 1 percent level by our method, Method 3 (the Nikkei225 index only) and Method 4 (the SP500 plus 
Nikkei225 indices). Across 16 funds, the average daily profit that our method can exploit Method 2 is 0.200 percent (annualized to 50 percent) and the associated average $t$-statistic is 4.278, whereas the respective numbers for Method 3 (the Nikkei225 alone) are 0.204 percent and 4.292. Therefore, our method and Method 3 appear to be roughly equally efficient, and both methods are more effective than Method 4 in exploiting Method 2.

Panel C shows that Method 3 (the Nikkei225 alone) can be exploited profitably at the 5 percent significance level for the 16 funds by all alternative methods except the stale price. Comparing Panels B and C, it is interesting to note that Methods 2 and 3 in general can exploit each other. This is possible because each method employs partial information arrived at the market to estimate the true stock prices at U.S. close. If one variable (say the S\&P500 index) contains some information that is not contained by the other variable (say the Nikkei225 index), we can expect one method to be able to profit from the other and vice versa. Among the three competing methods to exploit Method 3, our method appears to be the best in that our implied $t$ statistics are the highest for each fund. For all 16 funds, the average daily profit that our method can exploit Method 3 is 0.176 percent with an average $t$-statistic of 3.676. This profitability is annualized to be an economically important 44 percent.

Panel D demonstrates that our method can profit from Method 4 (the S\&P500 and Nikkei225 combined) at the 5 percent significance level for 10 out of 16 funds, and at the 10 percent for 4 additional funds. The average profit over the 16 funds is 0.092 percent which is annualized at 23 percent. However, none of the other competing method can significantly profit from Method 4 for any fund. Comparing the results in Panel D with those in Panels B and C, we can see that Method 4 can significantly exploit Methods 2 and 3, but not the other way around. Therefore it is important to combine information contained in both the S\&P500 and the Nikkei225 indices. 
Lastly, Panel E of Table IV shows that Method 5 (the stale price) is highly vulnerable to speculation by all four fair price estimates, and our method is clearly the best method in exploiting the stale price. The average daily profit that our method can exploit from stale pricing is 0.296 percent with an average $t$-statistic of 6.878 . This daily return translates into an economically significant figure of 75 percent per year.

The above analysis based on the benchmark of holding the U.S. T-bill demonstrates that our method indeed provides the most accurate estimate of the true price than all alternative methods in the sense that our fair price estimate is the most successful in preventing exploitation by the alternatives. The stale price is apparently the worst estimate, followed by Method 2 and Method 3. Method 4 which combines the S\&P500 and Nikkei225 futures indices employs more information than the other two methods and is the best competitor with our method.

Organized in the same manner, Table V reports the results using the benchmark of buying-and-holding the mutual fund under investigation. This table provides much of the same information as that contained in Table IV. Two interesting observations are worth making. As shown in Panel A of Table V, Method 4 (our best competitor) can exploit profitably our method at the 5 percent significance level for one fund (Fund 3). On the other hand, Panel D demonstrates that our method can profit from Method 4 at the 5 percent significance level for all 16 funds with an average $t$-statistic of 2.118 . The average profit over 16 funds is 0.100 percent which is annualized at 25 percent.

In summary, the results reported in this section accord well with intuition and suggest that our method is significantly better than the existing methods. This argument is based on two grounds. First, our method predicts the next-day opening security prices in Japan most accurately among all methods. Second, our method produces the best fair price at the U.S. close in that our stated price cannot be significantly exploited by other methods. Furthermore, for any stated price 
from an alternative method, our method in general can exploit the stated price significantly and it can do so more profitably than other competing methods.

\section{Robustness of Results}

In this section, we conduct a number of simulations to check for the robustness of our method's superiority over competing methods in pricing different types of funds. Firstly, we examine how the average stock size in a fund can affect the relative performance of all estimation methods. Secondly, we study the impact of portfolio turnover ratio on the forecast accuracy of the competing methods. Thirdly, we investigate how the number of stocks contained in a fund can affect the relative forecast accuracy. Lastly, we explore the possible effects of fund style (book-to-market ratio) on the relative performance of the estimation methods.

\section{A. Stock Size}

In general, small-cap stocks have relatively more idiosyncratic risks than large-cap stocks, and it may be more difficult to predict future prices of small-cap stocks than large-cap stocks using market-wide information. As a result, we may expect that the fair price of a fund consisting primarily of small-cap stocks may be more difficult to estimate than that of a fund consisting mainly of large-cap stocks, all else being equal. However, this may affect all estimation methods. How the average stock size in a fund affects the relative effectiveness of our method compared to alternative methods is an empirical question and is worth investigating.

We follow the procedure described in Section III to simulate three mutual funds, consisting, respectively, of large-cap, medium-cap and small-cap stocks. For each fund, we estimate the fair prices of the constituent stocks using the five methods and compute the RMSE of predicting the next-day open prices of the stocks in the Japanese market. The sample period 
for the simulation is identical to that of the actual funds. We conduct 400 simulations for each fund and report the average statistics over the 400 replications.

Our simulation results, organized in the similar manner to those in Table III, are reported in Table VI. As expected, the RMSE increases as the market-cap of stocks in a fund decreases, regardless of the estimation method used. Furthermore, we see that the market-caps of stocks affect the estimation accuracy to a similar extent across estimation methods. As in the case of the 16 actual funds, our method produces a significantly lower RMSE than all alternative methods for each of the size-sorted mutual funds. The $t$-statistics that our method beats an alternative method vary little across the simulated funds.

\section{B. Portfolio Turnover Ratio}

A higher portfolio turnover ratio of a mutual fund changes the stock composition in the fund more frequently and can in turn change the factor loadings of the portfolio systematically. How this will affect the performance of each estimation method is another empirical question worth examining. We simulate artificial funds with annual turnover ratios ranging from 10 percent to 1,000 percent. We carry out 400 simulations and report the average statistics over the 400 replications in Table VII.

Interestingly, we do not find a high sensitivity of the RMSE to the portfolio turnover ratio for each estimation method. For all estimation methods, the RMSEs are quite similar at different turnover ratios. Furthermore, we do not find that the relative performance of our estimation method changes with respect to the portfolio turnover ratio, as justified by the stable $t$-statistics across funds sorted by turnover ratio. Our method consistently outperforms all alternative methods for all funds regardless of the portfolio turnover ratio. 


\section{Number of Stocks in a Fund}

Our third experiment examines the effect of the number of stocks in a fund on the relative forecast accuracy of fund prices for the various estimation methods. This exercise is warranted because when the number of stocks in a fund increases, the improvement in forecast accuracy may vary across different methods. In other words, some methods may be more suitable for funds with a small number of stocks, while other methods may be more suitable for funds with a larger number of stocks in its portfolio. In this case, our approach of estimating individual stock prices may not be obviously superior to the alternative approaches which adjust prices at the fund level for funds with a given number of stocks. We simulate 5 funds with the number of stocks in each fund ranging from 25 up to 500 stocks. Estimation results are reported in Table VIII.

We observe a clear pattern that the RMSE monotonically decreases as the number of stocks in a fund increases for all estimation methods. This is because in general the more the number of stocks in a fund, the more diversified the portfolio is, and the more accurately the price of the fund can be predicted by any estimation method. Regardless of the number of stocks in a fund, our method produces a lower RMSE than all alternative methods at the 5 percent significance level.

Interestingly, as the number of stocks in a fund increases, our method seems to benefit relatively more than other methods in terms of forecasting accuracy. We can see that the $t$ statistic (in absolute value) that our method outperforms an alternative method increases monotonically with the number of stocks in a fund. While each method has the inherent uncertainty in estimating regression parameters, our stepwise regression can create an additional noise in choosing the right explanatory variables for each stock each time (albeit it has the benefit of using better signals when the right explanatory variables are chosen). When the 
number of stocks increases, the noise in choosing the explanatory variables may decrease relative to the signals captured in our stepwise regression at the portfolio level. We suspect that this may be the reason for why our method performs more favorably relative to other methods for a fund with more stocks than a fund with fewer stocks.

\section{Book-to-Market Ratio}

Our last experiment examines the performance of our method relative to other methods with respect to fund style in another dimension - the book-to-market ratio. To this end, we simulate three mutual funds, consisting, respectively, of high, medium and low book-to-market ratio stocks. Table IX shows the results.

All estimation methods seem to predict blend funds somewhat better than both value and growth funds, as is justified by the reported RMSEs. Our method outperforms Methods 2, 3 and 5 at the 1 percent significance level for all 3 types of funds, and Method 4 for two types of funds consisting of value and growth stocks. Our method beats Method 4 for the blend fund at the 5 percent significance level. Overall, we find that the superior performance of our method over other competing methods is not affected by fund style.

\section{Conclusion}

Recent researchers demonstrate that simple trading strategies using readily available information can significantly exploit pricing errors when international mutual funds use final transaction prices in a foreign exchange to compute daily share prices. To remove return predictability, the literature suggests estimating fair prices of fund shares at the portfolio level using market-wide information. This paper proposes a new methodology to provide fair prices of international fund shares by adjusting prices at the individual securities level using a broad set of 
information that are readily available publicly. To utilize information efficiently, we employ stepwise regression to endogenously determine the stock-specific optimal set of instruments in estimating the fair price of each stock in a fund. We provide a comprehensive evaluation of our approach along with existing methods using 16 U.S.-based mutual funds investing exclusively in Japanese stocks and obtain several interesting results.

Firstly, for all 16 funds, our method produces the most accurate prediction of fund prices at next-day Japan open, which are the best proxies for the unobserved prices at U.S. close. It outperforms all existing methods at the 5 percent significance level or better in terms of prediction root mean square errors. Secondly, while each existing method removes much of daily return predictability resulting from stale pricing, all of them remain highly vulnerable to speculative attacks. In particular, based on the benchmark of holding the U.S. T-bill, our method can profit from the methods that use either the S\&P500 or the Nikkei225 index significantly by 50 and 44 percent annualized returns, respectively. Our method can profit from the best alternative method which uses both the S\&P500 and Nikkei225 indices by an annualized return of 23 percent. Thirdly, our method is the most successful in preventing profitable strategic exploitation in that none of the competing methods can significantly profit from our stated price. Fourthly, simulation results show that our method is superior to existing methods regardless of the various fund styles that a mutual fund may have, including turnover ratio, stock size, number of stocks in a fund, and book-to-market ratio.

The mutual fund industry has various policies in place, such as front-end loads, redemption fees, and transaction restrictions, to deal with the pricing error problem. While these methods can diminish the opportunities for a market timer to trade daily, they do not prevent strategic timing of purchases and do not eliminate the dilution impact on the performance of the 
funds. Our method which is the least vulnerable to exploitation and can be easily implemented may thus provide a useful alternative approach to solving the stale pricing problem in practice. 


\section{References}

Becker, Kent G., Joseph Finnerty, and Manoj Gupta, 1990, The intertemporal relation between the U.S. and Japanese stock markets, Journal of Finance 45, 1297-1306.

Beckers, Stan, Gregory Connor, and Ross Curds, 1996, National versus global influences on equity returns, Financial Analysts Journal 52, 31-39.

Bhargava, Rahul, Ann Bose, and David A. Dubofsky, 1998, Exploiting international stock market correlations with open-end international mutual funds, Journal of Business Finance and Accounting 25, 765-773.

Bhargava, Rahul, and David A. Dubofsky, 2001, A note on fair value pricing of mutual funds, Journal of Banking and Finance 25, 339-354.

Boudoukh, Jacob, Matthew Richardson, Marti Subrahmanyam, and Robert F. Whitelaw, 2002, Stable prices and strategies for trading mutual funds, Financial Analysts Journal, 53-71.

Burns, Patrick, Robert Engle, and Joseph Mezrich, 1998, Correlations and volatilities of asynchronous data, Journal of Derivatives 5, 7-18.

Campbell, John Y., and Yasushi Hamao, 1992, Predictable stock returns in the United States and Japan: A study of long-term capital market integration, Journal of Finance 47, 43-69.

Carhart, Mark M., 1997, On persistence in mutual fund performance, Journal of Finance 52, 5782.

Chalmers, John M. R., Roger M. Edelen, and Gregory B. Kadlec, 2001, On the perils of financial intermediaries setting security prices: the mutual fund wild card option, Journal of Finance 56, 2209-2236.

Chan, Louis K. C., Yasushi Hamao, and Josef Lakonishok, 1991, Fundamentals and stock returns in Japan, Journal of Finance 46, 1739-1789.

Chan, Kalok, Allaudeen Hameed, and Sie Ting Lau, 2003, What if trading location is different from business location? Evidence from the Jardine Group, Journal of Finance 58, 12211246.

Draper, Norman R., and Harry Smith, 1998, Applied Regression Analysis, Wiley, New York.

Duffee, Gregory R., 2002, Term premia and interest rate forecasts in affine models, Journal of Finance 57, 405-443.

Dumas, Bernard, and Bruno Solnik, 1995, The world price of foreign exchange risk, Journal of Finance 50, 445-479.

Errunza, Vihang, and Etienne Losq, 1985, International asset pricing under mild segmentation: theory and test, Journal of Finance 40, 105-124. 
Eun, Cheol S., and Sundaram Janakiramanan, 1986, A model of international asset pricing with a constraint on the foreign equity ownership, Journal of Finance 41, 897-914.

Eun, Cheol S., and Sangdal Shim, 1989, International transmission of stock market movements, Journal of Financial and Quantitative Analysis 24, 241-256.

Fama, Eugene and Kenneth R. French, 1987, Commodity futures prices: some evidence on forecast power, premiums, and the theory of storage, Journal of Business 60, 55-73.

Fama, Eugene and Kenneth R. French, 1996, Multifactor explanations of asset-pricing anomalies, Journal of Finance 51, 55-84.

Fama, Eugene F., and Kenneth R. French, 1997, Industry costs of equity, Journal of Financial Economics 43, 153-193.

Fama, Eugene F., and Kenneth R. French, 1998, Value versus growth: the international evidence, Journal of Finance 53, 1975-1999.

Froot, Kenneth A., and Emil M. Dabora, 1999, How are stock prices affected by the location of trade? Journal of Financial Economics 53, 189-216.

Goetzmann, William N., Zoran Ivkovic, and K. Geert Rouwenhorst, 2001, Day trading international mutual funds: evidence and policy solutions, Journal of Financial and Quantitative Analysis 36, 287-309.

Greene, Jason T., and Charles W. Hodges, 2002. The dilution impact of daily fund flows on open-end mutual funds, Journal of Financial Economics 65, 131-158.

Griffin, John M., and G. Andrew Karolyi, 1998, Another look at the role of the industrial structure of markets for international diversification strategies, Journal of Financial Economics 50, 351-373.

Hamao, Yasushi, Ronald W. Masulis, and Victor Ng, 1990, Correlations in price changes and volatility across international stock markets, Review of Financial Studies 3, 281-307.

Hartzmark, Michael L., 1991, Luck versus forecast ability: determinants of trader performance in futures markets, Journal of Business 64, 49-74.

He, Jia, and Lilian K. Ng, 1998, The foreign exchange exposure of Japanese multinational corporations Journal of Finance 53, 733-753.

Heston, Steven L., and K. Geert Rouwenhorst, 1994, Does industrial structure explain the benefits of international diversification?, Journal of Financial Economics 36, 3-27.

Hilliard, Jimmy E., 1979, The relation between equity indices on world exchanges, Journal of Finance 34, 103-114. 
Jegadeesh, Narasimhan, and Sheridan Titman, 1993, Returns to buying winners and selling losers: Implications for stock market efficiency, Journal of Finance 48, 65-91.

Jorion, Philippe, 1990, The exchange-rate exposure of U. S. multinationals, Journal of Business 63, 331-345.

Karolyi, G. Andrew, and Rene M. Stulz, 1996, Why do markets move together? An investigation of U.S.-Japan stock return comovements, Journal of Finance 51, 951-986.

Killian, Lutz, and Mark P. Taylor, 2003, Why is it so difficult to beat the random walk forecast of exchange rates?, Journal of International Economics 60, 85-107.

Pesaran, M. Hashem, and Allan Timmermann, 1995, Predictability of stock returns: robustness and economic significance, Journal of Finance 50, 1201-1228.

Qi, Min, and Yangru Wu, 2003, Nonlinear prediction of exchange rates with monetary fundamentals, Journal of Empirical Finance 10, 623-640.

Rouwenhorst, K. Geert, 1998, International momentum strategies, Journal of Finance 53, 267284.

Williamson, Rohan G., 2001, Exchange rate exposure and competition: evidence from the automotive industry, Journal of Financial Economics 59, 441-75.

Zitzewitz, Eric, 2003, Who cares about shareholders? Arbitrage-proofing mutual funds, Journal of Law, Economics, and Organization 19, 245-280. 


\section{Table I. Descriptive Statistics of 16 U.S.-Based Japanese Mutual Funds}

This table provides sample statistics of 16 U.S.-based Japanese mutual funds. Columns 1-3 report the fund size, style, and number of stocks in a fund, respectively, where the fund size is denominated in million U.S. dollars. Column 4 reports the equal-weighted average of the book-to-market ratio. Column 5 reports the geometric average market capitalization of the fund's constituent stocks in million dollars. Columns 6-7 report the average annual turnover ratio and the proportion of the fund's assets held in stocks and cash, respectively. All the statistics are obtained from the March 2004 Morningstar CD, except for the bookto-market ratio. The Morningstar data are based on the funds' portfolio disclosure between December 31, 2002 and February 29, 2004. The book-to-market ratio is obtained from PACAP, averaged over the sample period, from January 2, 1991 to December 31, 2001.

\begin{tabular}{|c|c|c|c|c|c|c|c|}
\hline Fund Name & $\begin{array}{c}\text { Fund size } \\
(1)\end{array}$ & $\begin{array}{l}\text { Style } \\
(2)\end{array}$ & $\begin{array}{c}\text { Number } \\
\text { of stocks } \\
(3) \\
\end{array}$ & $\begin{array}{c}\text { Book-to- } \\
\text { market ratio } \\
(4)\end{array}$ & $\begin{array}{c}\text { Market } \\
\text { capitalization } \\
\text { (5) } \\
\end{array}$ & $\begin{array}{c}\text { Turnover } \\
\text { Ratio } \\
(6) \\
\end{array}$ & $\begin{array}{c}\text { Stocks and } \\
\text { cash holdings } \\
(7)\end{array}$ \\
\hline Commonwealth Japan & 9.0 & Medium value & 52 & 0.790 & 2,758 & 28 & 100 \\
\hline Credit Suisse Japan Equity Fund & 86.2 & Large growth & 49 & 0.772 & 11,193 & 117 & 99.2 \\
\hline Dimensional Japan Sm Co & 41.5 & Small value & 973 & 0.858 & 255 & 16 & 100 \\
\hline Dreyfus Premier Japan & 6.6 & Large blend & 52 & 0.779 & 5,589 & 167 & 100 \\
\hline Fidelity Advisor Japan & 19.3 & Large value & 71 & 0.779 & 9,501 & 99 & 100 \\
\hline Fidelity Japan & 670.3 & Large growth & 100 & 0.724 & 7,121 & 86 & 100 \\
\hline Fidelity Japan Smaller Companies & 1149.1 & Medium growth & 167 & 0.874 & 966 & 43 & 100 \\
\hline GAM Japan Capital Fund & 1.8 & Large blend & 66 & 0.827 & 8,844 & 127 & 100 \\
\hline Goldman Sachs Japanese & 58.6 & Large growth & 86 & 0.769 & 8,596 & 115 & 100 \\
\hline Japan S & 468.4 & Large growth & 109 & 0.811 & 5,524 & 80 & 100 \\
\hline Japan Smaller Companies & 4.7 & Small growth & 33 & 0.583 & 479 & 39 & 98.5 \\
\hline JPMorgan Fleming Japan Fund & 15.6 & Medium blend & 108 & 0.779 & 2,123 & 797 & 99.7 \\
\hline Matthews Japan & 16.4 & Medium growth & 33 & 0.724 & 3,014 & 77 & 100 \\
\hline Morgan Stanley Instl:Japanese Value Equity & 32.5 & Large blend & 66 & 0.729 & 7,050 & 79 & 100 \\
\hline Scudder Japanese Equity & 26.7 & Large growth & 63 & 0.605 & 11,908 & 137 & 100 \\
\hline T. Rowe Price Japan & 194.6 & Large growth & 82 & 0.811 & 4,472 & 255 & 96.2 \\
\hline Mean & 175.1 & & 132 & 0.763 & 5,587 & 141 & 99.6 \\
\hline Median & 29.6 & & 69 & 0.779 & 5,557 & 93 & 100.0 \\
\hline Standard Deviation & 304.1 & & 214 & 0.074 & 3,553 & 174 & 0.9 \\
\hline
\end{tabular}




\section{Table II. Explanatory Variables of Stepwise Regressions}

This table provides sample statistics as well as cross correlations of the independent variables used in our stepwise regressions. Columns 1-2 report the daily mean return and standard deviation of the variables (in percent) over the sample period. Column 3 reports the proportion of times (in percent) a particular variable is selected into the final regression model. The cross correlations of these variables are reported in Columns 4-11, where the correlations with the industry portfolios (ADRs) represent the average of all industries (ADRs). The daily returns on the dollar-yen rate is measured from Japan close to U.S. close. For the rest of factors, returns are measured from U.S. close to the next-day U.S. close. The sample period is from January 2, 1991 to December 31, 2001.

\begin{tabular}{|c|c|c|c|c|c|c|c|c|c|c|c|}
\hline \multirow[b]{2}{*}{$\begin{array}{c}\text { Explanatory } \\
\text { Variables }\end{array}$} & \multirow[b]{2}{*}{$\begin{array}{c}\text { Mean } \\
\text { return } \\
(1)\end{array}$} & \multirow[b]{2}{*}{$\begin{array}{c}\text { Standard } \\
\text { deviation } \\
(2) \\
\end{array}$} & \multirow[b]{2}{*}{$\begin{array}{c}\text { Proportion } \\
\text { (3) }\end{array}$} & \multicolumn{8}{|c|}{ Cross Correlations } \\
\hline & & & & $\begin{array}{c}\text { Nikkei } \\
225 \\
\text { Futures } \\
(4) \\
\end{array}$ & $\begin{array}{c}\text { Japan } \\
\text { ETF } \\
(5) \\
\end{array}$ & $\begin{array}{c}\text { Dollar- } \\
\text { yen rate } \\
(6)\end{array}$ & $\begin{array}{c}\text { SMB } \\
\text { factor } \\
(7) \\
\end{array}$ & $\begin{array}{c}\text { HML } \\
\text { factor } \\
(8) \\
\end{array}$ & $\begin{array}{c}\text { Momentum } \\
\text { factor } \\
(9) \\
\end{array}$ & $\begin{array}{c}\text { Industry } \\
\text { Portfolio } \\
(10) \\
\end{array}$ & $\begin{array}{c}\text { ADRs } \\
(11)\end{array}$ \\
\hline S\&P500 Futures & 0.040 & 1.032 & 42.92 & 0.41 & 0.43 & -0.08 & -0.32 & -0.60 & 0.09 & -0.18 & 0.33 \\
\hline Nikkei 225 Futures & -0.023 & 1.536 & 66.24 & 1.00 & 0.75 & -0.06 & -0.07 & -0.27 & 0.00 & -0.07 & 0.70 \\
\hline Japan ETF & -0.027 & 1.795 & 8.29 & & 1.00 & 0.31 & -0.06 & -0.31 & -0.02 & -0.08 & 0.79 \\
\hline Dollar-yen rate & 0.012 & 0.608 & 94.00 & & & 1.00 & 0.01 & 0.03 & 0.00 & 0.01 & 0.24 \\
\hline SMB factor & 0.003 & 0.570 & 2.06 & & & & 1.00 & -0.23 & 0.08 & 0.11 & 0.01 \\
\hline HML factor & 0.018 & 0.628 & 1.88 & & & & & 1.00 & -0.16 & 0.18 & -0.24 \\
\hline Momentum factor & 0.047 & 0.732 & 1.78 & & & & & & 1.00 & -0.04 & -0.02 \\
\hline Industry portfolios & -0.002 & 0.814 & 2.02 & & & & & & & 1.00 & -0.05 \\
\hline ADRs & 0.028 & 3.164 & 4.49 & & & & & & & & 1.00 \\
\hline
\end{tabular}




\section{Table III. Forecasting Accuracy of Alternative Fair Pricing Estimation Methods for 16 U.S.-Based Japanese Mutual Funds}

This table reports the out-of-sample forecasting performance of alternative fair-pricing estimation methods for 16 U.S.-based Japanese mutual funds. The methods investigated are: 1 . our proposed method which adjusts asset prices at the securities level using stepwise regressions; 2 . adjust asset price at the portfolio level using the S\&P500 futures index alone; 3. adjust asset price at the portfolio level using the Nikkei225 futures index alone; 4 . adjust asset price at the portfolio level using the S\&P500 and Nikkei225 futures indices combined; and 5. stale price without adjustment. Panel A displays the RMSE (in percent) of predicting asset prices at next-day Japan open. Panel B reports the $t$-statistic that our method 1 yields a lower RMSE than an alternative method. A $t$-statistic lower than -1.96 (-2.58) indicates that our method outperforms an alternative method at the 5 (1) percent significance level in terms of forecasting accuracy. Both RMSEs and $t$-statistics are averages over 400 simulations.

\begin{tabular}{|c|c|c|c|c|c|c|c|c|c|c|c|c|c|c|c|c|c|}
\hline Fund No. & 1 & 2 & 3 & 4 & 5 & 6 & 7 & 8 & 9 & 10 & 11 & 12 & 13 & 14 & 15 & 16 & Ave \\
\hline \multicolumn{18}{|c|}{ Panel A. RMSE of Predicting Security Price at Next-Day Japan Open } \\
\hline Method 1 & 0.659 & 0.636 & 0.576 & 0.618 & 0.623 & 0.644 & 0.639 & 0.614 & 0.611 & 0.605 & 0.770 & 0.602 & 0.658 & 0.617 & 0.635 & 0.602 & 0.632 \\
\hline Method 2 & 0.699 & 0.680 & 0.631 & 0.663 & 0.669 & 0.687 & 0.687 & 0.659 & 0.658 & 0.651 & 0.810 & 0.650 & 0.701 & 0.663 & 0.678 & 0.648 & 0.677 \\
\hline Method 3 & 0.725 & 0.701 & 0.638 & 0.681 & 0.689 & 0.709 & 0.699 & 0.679 & 0.677 & 0.673 & 0.814 & 0.655 & 0.719 & 0.686 & 0.698 & 0.662 & 0.694 \\
\hline Method 4 & 0.677 & 0.657 & 0.592 & 0.638 & 0.645 & 0.664 & 0.656 & 0.635 & 0.632 & 0.626 & 0.781 & 0.620 & 0.677 & 0.639 & 0.655 & 0.621 & 0.651 \\
\hline Method 5 & 0.797 & 0.775 & 0.726 & 0.757 & 0.766 & 0.784 & 0.780 & 0.756 & 0.756 & 0.752 & 0.883 & 0.734 & 0.793 & 0.764 & 0.773 & 0.740 & 0.771 \\
\hline \multicolumn{18}{|c|}{ Panel B. $t$-Statistic That Our Method 1 Yields a Lower RMSE Than an Alternative Method } \\
\hline Method 2 & -4.483 & -5.000 & -5.672 & -5.162 & -5.139 & -4.976 & -5.272 & -5.230 & -5.313 & -5.314 & -4.200 & -5.620 & -4.798 & -5.192 & -4.943 & -5.378 & -5.106 \\
\hline Method 3 & -5.916 & -6.224 & -6.976 & -6.281 & -6.342 & -6.239 & -6.229 & -6.370 & -6.384 & -6.517 & -5.039 & -6.270 & -5.947 & -6.336 & -6.203 & -6.354 & -6.227 \\
\hline Method 4 & -2.562 & -3.009 & -2.565 & -2.956 & -3.072 & -2.979 & -2.595 & -3.113 & -3.151 & -3.172 & -1.618 & -2.749 & -2.681 & -3.171 & -2.969 & -2.901 & -2.829 \\
\hline Method 5 & -8.313 & -8.732 & -9.056 & -8.859 & -8.903 & -8.684 & -8.848 & -8.946 & -8.976 & -9.054 & -7.543 & -9.133 & -8.451 & -8.905 & -8.743 & -8.985 & -8.758 \\
\hline
\end{tabular}




\section{Table IV. Average Profitability Exploitable by an Alternative Estimation Method for 16 U.S.-Based Japanese Mutual Funds Benchmark: Holding U.S. T-bill}

In this table, each panel reports the profitability of one fair-pricing estimation method exploitable by other competing methods for 16 U.S.-based Japanese mutual funds. The methods investigated are: 1 . our proposed method which adjusts asset prices at the securities level using stepwise regressions; 2 . adjust asset price at the portfolio level using the S\&P500 futures index alone; 3. adjust asset price at the portfolio level using the Nikkei225 futures index alone; 4 . adjust asset price at the portfolio level using the S\&P500 and Nikkei225 futures indices combined; and 5. stale price without adjustment. The returns are daily averages (in percent) relative to the benchmark of holding U.S. T-bill. A $t$-statistic larger than 1.96 (2.58) indicates that the estimation method can be exploited by an alternative method at the 5 (1) percent significance level. Both returns and $t$-statistics are averages over 400 simulations.

\begin{tabular}{|c|c|c|c|c|c|c|c|c|c|c|c|c|c|c|c|c|c|c|}
\hline Fund & & 1 & 2 & 3 & 4 & 5 & 6 & 7 & 8 & 9 & 10 & 11 & 12 & 13 & 14 & 15 & 16 & Ave \\
\hline \multicolumn{19}{|c|}{ Panel A. Method 1 to Be Exploited } \\
\hline \multirow[t]{2}{*}{ By method 2} & Return & 0.043 & 0.046 & -0.001 & 0.041 & 0.041 & 0.046 & 0.020 & 0.044 & 0.039 & 0.039 & 0.012 & 0.026 & 0.041 & 0.045 & 0.047 & 0.035 & 0.035 \\
\hline & t-ratio & 0.923 & 1.005 & -0.029 & 0.920 & 0.911 & 1.003 & 0.424 & 0.985 & 0.876 & 0.882 & 0.226 & 0.597 & 0.892 & 0.995 & 1.037 & 0.786 & 0.777 \\
\hline \multirow[t]{2}{*}{ By method 3} & Return & 0.018 & 0.018 & -0.063 & 0.014 & 0.014 & 0.019 & -0.013 & 0.017 & 0.014 & 0.010 & -0.012 & 0.005 & 0.011 & 0.016 & 0.020 & 0.004 & 0.006 \\
\hline & t-ratio & 0.358 & 0.365 & -1.319 & 0.292 & 0.287 & 0.374 & -0.280 & 0.347 & 0.280 & 0.206 & -0.234 & 0.114 & 0.222 & 0.314 & 0.397 & 0.082 & 0.113 \\
\hline \multirow[t]{2}{*}{ By method 4} & Return & 0.060 & 0.067 & 0.039 & 0.064 & 0.062 & 0.067 & 0.055 & 0.063 & 0.063 & 0.059 & 0.048 & 0.063 & 0.065 & 0.061 & 0.065 & 0.062 & 0.060 \\
\hline & t-ratio & 1.235 & 1.413 & 0.796 & 1.369 & 1.310 & 1.395 & 1.150 & 1.351 & 1.362 & 1.274 & 0.910 & 1.377 & 1.358 & 1.305 & 1.371 & 1.353 & 1.271 \\
\hline \multirow[t]{2}{*}{ By method 5} & Return & 0.038 & 0.032 & -0.051 & 0.025 & 0.025 & 0.034 & -0.006 & 0.028 & 0.023 & 0.023 & -0.023 & -0.002 & 0.026 & 0.029 & 0.033 & 0.013 & 0.015 \\
\hline & t-ratio & 0.787 & 0.670 & -1.094 & 0.534 & 0.527 & 0.710 & -0.144 & 0.606 & 0.497 & 0.487 & -0.464 & -0.058 & 0.530 & 0.606 & 0.701 & 0.290 & 0.324 \\
\hline \multicolumn{19}{|c|}{ Panel B. Method 2 to Be Exploited } \\
\hline \multirow[t]{2}{*}{ By method 1} & $\mathrm{R}$ & 0.182 & 0.197 & 0.216 & 0.198 & 0.197 & 0.196 & 0.213 & 0.195 & 0.199 & 0.195 & 0.219 & 0.210 & 0.197 & 0.193 & 0.194 & 0.203 & 0.200 \\
\hline & & 3.869 & 4.202 & 4.618 & 4.289 & 4.249 & 4.166 & 4.498 & 4.235 & 4.338 & 4.270 & 4.203 & 4.596 & 4.146 & 4.188 & 4.160 & 4.415 & 4.278 \\
\hline \multirow[t]{2}{*}{ By method 3} & $\operatorname{Re}$ & 0.176 & 0.201 & 0.219 & 0.206 & 0.199 & 0.199 & 0.211 & 0.201 & 0.205 & 0.199 & 0.219 & 0.221 & 0.200 & 0.195 & 0.201 & 0.209 & 0.204 \\
\hline & t-ratio & 3.686 & 4.250 & 4.569 & 4.379 & 4.250 & 4.197 & 4.355 & 4.330 & 4.401 & 4.316 & 4.144 & 4.745 & 4.143 & 4.183 & 4.261 & 4.467 & 4.292 \\
\hline \multirow[t]{2}{*}{ By method 4} & return & 0.153 & 0.167 & 0.194 & 0.171 & 0.166 & 0.168 & 0.185 & 0.167 & 0.170 & 0.165 & 0.197 & 0.194 & 0.166 & 0.162 & 0.166 & 0.178 & 0.173 \\
\hline & t-ratio & 3.141 & 3.470 & 4.103 & 3.595 & 3.473 & 3.459 & 3.836 & 3.505 & 3.591 & 3.502 & 3.734 & 4.203 & 3.401 & 3.387 & 3.461 & 3.787 & 3.603 \\
\hline \multirow[t]{2}{*}{ By method 5} & return & 0.045 & 0.056 & 0.024 & 0.052 & 0.045 & 0.058 & 0.038 & 0.052 & 0.049 & 0.047 & 0.030 & 0.046 & 0.045 & 0.046 & 0.054 & 0.051 & 0.046 \\
\hline & t-ratio & 0.928 & 1.172 & 0.504 & 1.094 & 0.946 & 1.196 & 0.800 & 1.097 & 1.038 & 1.009 & 0.568 & 0.995 & 0.937 & 0.975 & 1.135 & 1.091 & 0.968 \\
\hline
\end{tabular}


Table IV. (Continued)

\begin{tabular}{|c|c|c|c|c|c|c|c|c|c|c|c|c|c|c|c|c|c|c|}
\hline Fund & & 1 & 2 & 3 & 4 & 5 & 6 & 7 & 8 & 9 & 10 & 11 & 12 & 13 & 14 & 15 & 16 & Ave \\
\hline \multicolumn{19}{|c|}{ Panel C. Method 3 to Be Exploited } \\
\hline \multirow[t]{2}{*}{ By method 1} & Return & 0.170 & 0.182 & 0.176 & 0.178 & 0.177 & 0.181 & 0.178 & 0.178 & 0.177 & 0.179 & 0.160 & 0.170 & 0.177 & 0.179 & 0.180 & 0.179 & 0.176 \\
\hline & t-ratio & 3.555 & 3.828 & 3.471 & 3.763 & 3.754 & 3.803 & 3.601 & 3.801 & 3.766 & 3.823 & 2.975 & 3.594 & 3.670 & 3.829 & 3.795 & 3.791 & 3.676 \\
\hline \multirow[t]{2}{*}{ By method 2} & return & 0.130 & 0.131 & 0.114 & 0.127 & 0.124 & 0.132 & 0.127 & 0.125 & 0.124 & 0.124 & 0.118 & 0.119 & 0.127 & 0.124 & 0.127 & 0.127 & 0.125 \\
\hline & t-ratio & 2.754 & 2.808 & 2.392 & 2.766 & 2.673 & 2.808 & 2.684 & 2.720 & 2.693 & 2.701 & 2.284 & 2.639 & 2.685 & 2.683 & 2.722 & 2.799 & 2.676 \\
\hline \multirow[t]{2}{*}{ By method 4} & return & 0.164 & 0.165 & 0.147 & 0.161 & 0.161 & 0.164 & 0.151 & 0.164 & 0.161 & 0.162 & 0.136 & 0.146 & 0.158 & 0.164 & 0.163 & 0.156 & 0.158 \\
\hline & t-ratio & 3.462 & 3.495 & 2.981 & 3.414 & 3.416 & 3.460 & 3.091 & 3.515 & 3.441 & 3.490 & 2.545 & 3.139 & 3.295 & 3.517 & 3.461 & 3.325 & 3.315 \\
\hline \multirow[t]{2}{*}{ By method 5} & return & 0.019 & 0.040 & 0.028 & 0.041 & 0.031 & 0.039 & 0.037 & 0.034 & 0.034 & 0.032 & 0.033 & 0.043 & 0.036 & 0.024 & 0.036 & 0.043 & 0.034 \\
\hline & t-ratio & 0.397 & 0.808 & 0.555 & 0.851 & 0.631 & 0.797 & 0.746 & 0.695 & 0.710 & 0.663 & 0.609 & 0.889 & 0.726 & 0.499 & 0.737 & 0.896 & 0.700 \\
\hline \multicolumn{19}{|c|}{ Panel D. Method 4 to Be Exploited } \\
\hline \multirow[t]{2}{*}{ By method 1} & return & 0.092 & 0.102 & 0.048 & 0.098 & 0.099 & 0.101 & 0.082 & 0.101 & 0.095 & 0.097 & 0.081 & 0.085 & 0.096 & 0.102 & 0.104 & 0.092 & 0.092 \\
\hline & t-ratio & 1.913 & 2.140 & 0.985 & 2.072 & 2.085 & 2.108 & 1.658 & 2.132 & 2.019 & 2.072 & 1.501 & 1.799 & 1.969 & 2.152 & 2.178 & 1.941 & 1.920 \\
\hline \multirow[t]{2}{*}{ By method 2} & return & 0.022 & 0.033 & -0.006 & 0.031 & 0.031 & 0.031 & 0.017 & 0.033 & 0.030 & 0.029 & 0.008 & 0.019 & 0.031 & 0.033 & 0.032 & 0.027 & 0.025 \\
\hline & t-ratio & 0.495 & 0.739 & -0.120 & 0.700 & 0.700 & 0.684 & 0.366 & 0.742 & 0.681 & 0.669 & 0.154 & 0.439 & 0.678 & 0.745 & 0.728 & 0.622 & 0.564 \\
\hline \multirow[t]{2}{*}{ By method 3} & return & -0.006 & 0.006 & -0.048 & 0.003 & 0.003 & 0.007 & -0.011 & 0.003 & 0.002 & 0.000 & -0.019 & -0.007 & 0.003 & 0.003 & 0.006 & -0.001 & -0.003 \\
\hline & t-ratio & -0.131 & 0.121 & -0.952 & 0.063 & 0.056 & 0.132 & -0.217 & 0.055 & 0.036 & 0.006 & -0.360 & -0.138 & 0.060 & 0.054 & 0.128 & -0.014 & -0.069 \\
\hline \multirow[t]{2}{*}{ By method 5} & return & 0.013 & 0.027 & -0.003 & 0.025 & 0.024 & 0.025 & 0.013 & 0.027 & 0.025 & 0.025 & 0.003 & 0.014 & 0.023 & 0.025 & 0.027 & 0.022 & 0.020 \\
\hline & t-ratio & 0.280 & 0.561 & -0.063 & 0.542 & 0.509 & 0.518 & 0.270 & 0.569 & 0.530 & 0.526 & 0.052 & 0.301 & 0.481 & 0.532 & 0.571 & 0.478 & 0.416 \\
\hline \multicolumn{19}{|c|}{ Panel E. Method 5 to Be Exploited } \\
\hline \multirow[t]{2}{*}{ By method 1} & return & 0.276 & 0.292 & 0.318 & 0.293 & 0.295 & 0.291 & 0.306 & 0.294 & 0.295 & 0.295 & 0.305 & 0.301 & 0.292 & 0.295 & 0.291 & 0.296 & 0.296 \\
\hline & t-ratio & 6.389 & 6.832 & 7.318 & 6.912 & 6.938 & 6.770 & 6.984 & 6.966 & 7.009 & 7.042 & 6.260 & 7.114 & 6.690 & 7.005 & 6.819 & 7.004 & 6.878 \\
\hline \multirow[t]{2}{*}{ By method 2} & Return & 0.194 & 0.197 & 0.172 & 0.193 & 0.196 & 0.197 & 0.187 & 0.197 & 0.196 & 0.196 & 0.172 & 0.181 & 0.193 & 0.199 & 0.196 & 0.189 & 0.191 \\
\hline & t-ratio & 4.640 & 4.789 & 4.165 & 4.759 & 4.802 & 4.772 & 4.456 & 4.864 & 4.850 & 4.883 & 3.685 & 4.508 & 4.597 & 4.899 & 4.774 & 4.681 & 4.633 \\
\hline \multirow[t]{2}{*}{ By method 3} & return & 0.271 & 0.282 & 0.314 & 0.285 & 0.285 & 0.280 & 0.302 & 0.283 & 0.287 & 0.283 & 0.313 & 0.300 & 0.285 & 0.283 & 0.281 & 0.290 & 0.289 \\
\hline & t-ratio & 6.083 & 6.418 & 7.163 & 6.575 & 6.555 & 6.345 & 6.787 & 6.560 & 6.662 & 6.588 & 6.367 & 7.031 & 6.378 & 6.536 & 6.400 & 6.753 & 6.575 \\
\hline \multirow[t]{2}{*}{ By method 4} & return & 0.269 & 0.278 & 0.299 & 0.279 & 0.279 & 0.276 & 0.294 & 0.278 & 0.281 & 0.278 & 0.299 & 0.295 & 0.279 & 0.278 & 0.276 & 0.284 & 0.283 \\
\hline & t-ratio & 6.203 & 6.475 & 6.927 & 6.587 & 6.567 & 6.412 & 6.743 & 6.579 & 6.664 & 6.629 & 6.150 & 7.006 & 6.383 & 6.579 & 6.445 & 6.743 & 6.568 \\
\hline
\end{tabular}




\section{Table V. Average Profitability Exploitable by an Alternative Estimation Method for 16 U.S.-Based Japanese Mutual Funds Benchmark: Buy-and-hold Mutual Fund}

In this table, each panel reports the profitability of one fair-pricing estimation method exploitable by other competing methods for 16 U.S.-based Japanese mutual funds. The methods investigated are: 1 . our proposed method which adjusts asset prices at the securities level using stepwise regressions; 2 . adjust asset price at the portfolio level using the S\&P500 futures index alone; 3. adjust asset price at the portfolio level using the Nikkei225 futures index alone; 4 . adjust asset price at the portfolio level using the S\&P500 and Nikkei225 futures indices combined; and 5. stale price without adjustment. The returns are daily averages (in percent) relative to the benchmark of buying-and-holding the mutual fund under investigation. A $t$-statistic larger than 1.96 (2.58) indicates that the estimation method can be exploited by an alternative method at the 5 (1) percent significance level. Both returns and $t$-statistics are averages over 400 simulations.

\begin{tabular}{|c|c|c|c|c|c|c|c|c|c|c|c|c|c|c|c|c|c|c|}
\hline Fund & & 1 & 2 & 3 & 4 & 5 & 6 & 7 & 8 & 9 & 10 & 11 & 12 & 13 & 14 & 15 & 16 & Ave \\
\hline \multicolumn{19}{|c|}{ Panel A. Method 1 to Be Exploited } \\
\hline \multirow[t]{2}{*}{ By method 2} & return & 0.057 & 0.043 & 0.072 & 0.042 & 0.043 & 0.045 & 0.051 & 0.042 & 0.041 & 0.043 & 0.070 & 0.039 & 0.049 & 0.045 & 0.044 & 0.041 & 0.048 \\
\hline & t-ratio & 1.151 & 0.863 & 1.424 & 0.856 & 0.879 & 0.897 & 1.002 & 0.852 & 0.838 & 0.888 & 1.273 & 0.806 & 0.979 & 0.918 & 0.879 & 0.836 & 0.959 \\
\hline \multirow[t]{2}{*}{ By method 3} & return & 0.025 & 0.009 & 0.008 & 0.009 & 0.010 & 0.011 & 0.014 & 0.008 & 0.010 & 0.008 & 0.041 & 0.014 & 0.013 & 0.009 & 0.010 & 0.005 & 0.013 \\
\hline & t-ratio & 0.539 & 0.198 & 0.175 & 0.206 & 0.230 & 0.242 & 0.291 & 0.188 & 0.218 & 0.188 & 0.789 & 0.309 & 0.285 & 0.208 & 0.212 & 0.121 & 0.275 \\
\hline \multirow[t]{2}{*}{ By method 4} & return & 0.069 & 0.059 & 0.109 & 0.060 & 0.059 & 0.060 & 0.083 & 0.056 & 0.061 & 0.058 & 0.103 & 0.073 & 0.069 & 0.056 & 0.056 & 0.065 & 0.069 \\
\hline & t-ratio & 1.446 & 1.238 & 2.293 & 1.278 & 1.246 & 1.262 & 1.717 & 1.185 & 1.297 & 1.246 & 1.955 & 1.573 & 1.421 & 1.192 & 1.183 & 1.382 & 1.432 \\
\hline \multirow[t]{2}{*}{ By method 5} & return & 0.046 & 0.023 & 0.018 & 0.021 & 0.022 & 0.027 & 0.021 & 0.021 & 0.020 & 0.021 & 0.030 & 0.007 & 0.028 & 0.023 & 0.024 & 0.015 & 0.023 \\
\hline & t-ratio & 0.963 & 0.494 & 0.369 & 0.439 & 0.461 & 0.567 & 0.420 & 0.438 & 0.426 & 0.459 & 0.574 & 0.147 & 0.584 & 0.491 & 0.505 & 0.318 & 0.478 \\
\hline \multicolumn{19}{|c|}{ Panel B. Method 2 to Be Exploited } \\
\hline \multirow[t]{2}{*}{ By method 1} & return & 0.178 & 0.173 & 0.261 & 0.178 & 0.178 & 0.175 & 0.220 & 0.172 & 0.180 & 0.178 & 0.250 & 0.198 & 0.184 & 0.173 & 0.170 & 0.186 & 0.191 \\
\hline & t-ratio & 4.133 & 4.143 & 6.297 & 4.326 & 4.289 & 4.142 & 5.227 & 4.176 & 4.383 & 4.339 & 5.422 & 4.955 & 4.333 & 4.165 & 4.072 & 4.586 & 4.562 \\
\hline \multirow[t]{2}{*}{ By method 3} & return & 0.171 & 0.176 & 0.261 & 0.183 & 0.180 & 0.177 & 0.216 & 0.177 & 0.184 & 0.182 & 0.247 & 0.207 & 0.185 & 0.174 & 0.175 & 0.191 & 0.193 \\
\hline & t-ratio & 4.070 & 4.261 & 6.433 & 4.521 & 4.393 & 4.233 & 5.246 & 4.345 & 4.554 & 4.481 & 5.441 & 5.261 & 4.444 & 4.247 & 4.229 & 4.801 & 4.685 \\
\hline \multirow[t]{2}{*}{ By method 4} & return & 0.150 & 0.147 & 0.246 & 0.154 & 0.150 & 0.148 & 0.196 & 0.147 & 0.154 & 0.151 & 0.232 & 0.187 & 0.156 & 0.145 & 0.145 & 0.165 & 0.167 \\
\hline & t-ratio & 3.609 & 3.599 & 5.988 & 3.840 & 3.722 & 3.619 & 4.727 & 3.658 & 3.853 & 3.797 & 5.079 & 4.728 & 3.764 & 3.597 & 3.571 & 4.155 & 4.082 \\
\hline \multirow[t]{2}{*}{ By method 5} & return & 0.045 & 0.040 & 0.082 & 0.039 & 0.034 & 0.042 & 0.056 & 0.036 & 0.038 & 0.038 & 0.073 & 0.046 & 0.040 & 0.034 & 0.037 & 0.043 & 0.045 \\
\hline & t-ratio & 1.072 & 0.945 & 1.933 & 0.948 & 0.827 & 1.007 & 1.311 & 0.873 & 0.915 & 0.928 & 1.550 & 1.113 & 0.948 & 0.810 & 0.890 & 1.054 & 1.070 \\
\hline
\end{tabular}


Table V. (Continued)

\begin{tabular}{|c|c|c|c|c|c|c|c|c|c|c|c|c|c|c|c|c|c|c|}
\hline Fund & & 1 & 2 & 3 & 4 & 5 & 6 & 7 & 8 & 9 & 10 & 11 & 12 & 13 & 14 & 15 & 16 & Ave \\
\hline \multicolumn{19}{|c|}{ Panel C. Method 3 to Be Exploited } \\
\hline \multirow[t]{2}{*}{ By method 1} & Return & 0.203 & 0.197 & 0.263 & 0.196 & 0.198 & 0.199 & 0.225 & 0.194 & 0.197 & 0.201 & 0.229 & 0.196 & 0.203 & 0.199 & 0.195 & 0.202 & 0.206 \\
\hline & t-ratio & 4.005 & 3.935 & 5.256 & 3.960 & 3.983 & 3.944 & 4.414 & 3.930 & 3.986 & 4.095 & 4.155 & 4.042 & 3.991 & 4.018 & 3.894 & 4.102 & 4.107 \\
\hline \multirow[t]{2}{*}{ By method 2} & return & 0.153 & 0.137 & 0.200 & 0.137 & 0.134 & 0.139 & 0.170 & 0.131 & 0.134 & 0.136 & 0.189 & 0.143 & 0.144 & 0.131 & 0.131 & 0.143 & 0.147 \\
\hline & t-ratio & 2.954 & 2.650 & 3.700 & 2.665 & 2.613 & 2.693 & 3.168 & 2.576 & 2.624 & 2.685 & 3.251 & 2.767 & 2.727 & 2.594 & 2.562 & 2.776 & 2.813 \\
\hline \multirow[t]{2}{*}{ By method 4} & return & 0.191 & 0.173 & 0.233 & 0.171 & 0.173 & 0.174 & 0.192 & 0.172 & 0.173 & 0.177 & 0.202 & 0.168 & 0.176 & 0.174 & 0.170 & 0.172 & 0.181 \\
\hline & t-ratio & 3.734 & 3.411 & 4.474 & 3.415 & 3.443 & 3.421 & 3.703 & 3.456 & 3.470 & 3.560 & 3.595 & 3.376 & 3.425 & 3.493 & 3.369 & 3.436 & 3.549 \\
\hline \multirow[t]{2}{*}{ By method 5} & return & 0.019 & 0.022 & 0.088 & 0.028 & 0.019 & 0.024 & 0.055 & 0.017 & 0.022 & 0.022 & 0.078 & 0.043 & 0.030 & 0.010 & 0.018 & 0.036 & 0.033 \\
\hline & t-ratio & 0.399 & 0.454 & 1.688 & 0.571 & 0.380 & 0.479 & 1.076 & 0.346 & 0.451 & 0.444 & 1.397 & 0.861 & 0.592 & 0.200 & 0.368 & 0.720 & 0.652 \\
\hline \multicolumn{19}{|c|}{ Panel D. Method 4 to Be Exploited } \\
\hline \multirow[t]{2}{*}{ By method 1} & return & 0.103 & 0.096 & 0.115 & 0.095 & 0.098 & 0.096 & 0.107 & 0.095 & 0.093 & 0.098 & 0.132 & 0.092 & 0.100 & 0.099 & 0.096 & 0.093 & 0.100 \\
\hline & t-ratio & 2.136 & 2.045 & 2.341 & 2.042 & 2.093 & 2.039 & 2.230 & 2.040 & 2.008 & 2.115 & 2.515 & 2.016 & 2.085 & 2.118 & 2.056 & 2.017 & 2.118 \\
\hline \multirow[t]{2}{*}{ By method 2} & return & 0.036 & 0.029 & 0.066 & 0.031 & 0.032 & 0.028 & 0.047 & 0.029 & 0.031 & 0.032 & 0.065 & 0.031 & 0.038 & 0.032 & 0.027 & 0.032 & 0.037 \\
\hline & t-ratio & 0.698 & 0.570 & 1.285 & 0.606 & 0.638 & 0.553 & 0.914 & 0.578 & 0.611 & 0.641 & 1.163 & 0.623 & 0.739 & 0.633 & 0.542 & 0.642 & 0.715 \\
\hline \multirow[t]{2}{*}{ By method 3} & return & 0.004 & -0.001 & 0.022 & 0.000 & 0.001 & 0.001 & 0.016 & -0.004 & 0.000 & 0.000 & 0.033 & 0.003 & 0.006 & -0.001 & -0.002 & 0.001 & 0.005 \\
\hline & t-ratio & 0.088 & -0.026 & 0.468 & -0.005 & 0.017 & 0.021 & 0.342 & -0.083 & -0.009 & 0.001 & 0.651 & 0.061 & 0.141 & -0.031 & -0.036 & 0.030 & 0.102 \\
\hline \multirow[t]{2}{*}{ By method 5} & return & 0.023 & 0.019 & 0.066 & 0.022 & 0.022 & 0.019 & 0.040 & 0.020 & 0.022 & 0.024 & 0.057 & 0.023 & 0.027 & 0.021 & 0.019 & 0.024 & 0.028 \\
\hline & t-ratio & 0.493 & 0.410 & 1.343 & 0.469 & 0.466 & 0.403 & 0.828 & 0.425 & 0.481 & 0.517 & 1.057 & 0.495 & 0.558 & 0.441 & 0.402 & 0.516 & 0.582 \\
\hline \multicolumn{19}{|c|}{ Panel E. Method 5 to Be Exploited } \\
\hline \multirow[t]{2}{*}{ By method 1} & return & 0.304 & 0.303 & 0.391 & 0.306 & 0.310 & 0.303 & 0.346 & 0.305 & 0.310 & 0.312 & 0.365 & 0.320 & 0.311 & 0.310 & 0.301 & 0.312 & 0.319 \\
\hline & t-ratio & 6.963 & 7.098 & 9.532 & 7.321 & 7.358 & 7.065 & 8.169 & 7.265 & 7.444 & 7.494 & 7.877 & 7.970 & 7.211 & 7.353 & 7.069 & 7.614 & 7.550 \\
\hline \multirow[t]{2}{*}{ By method 2} & Return & 0.225 & 0.211 & 0.261 & 0.210 & 0.214 & 0.212 & 0.234 & 0.211 & 0.214 & 0.217 & 0.245 & 0.209 & 0.217 & 0.216 & 0.209 & 0.210 & 0.220 \\
\hline & t-ratio & 4.774 & 4.556 & 5.694 & 4.608 & 4.670 & 4.563 & 5.025 & 4.629 & 4.708 & 4.789 & 4.815 & 4.683 & 4.617 & 4.712 & 4.524 & 4.659 & 4.752 \\
\hline \multirow[t]{2}{*}{ By method 3} & return & 0.264 & 0.257 & 0.364 & 0.265 & 0.266 & 0.257 & 0.311 & 0.260 & 0.267 & 0.265 & 0.349 & 0.292 & 0.271 & 0.262 & 0.256 & 0.275 & 0.280 \\
\hline & t-ratio & 6.066 & 6.036 & 8.724 & 6.305 & 6.280 & 5.986 & 7.262 & 6.172 & 6.383 & 6.349 & 7.453 & 7.173 & 6.265 & 6.202 & 6.000 & 6.636 & 6.581 \\
\hline \multirow[t]{2}{*}{ By method 4} & return & 0.290 & 0.278 & 0.366 & 0.281 & 0.284 & 0.279 & 0.323 & 0.278 & 0.284 & 0.284 & 0.353 & 0.302 & 0.289 & 0.282 & 0.276 & 0.289 & 0.296 \\
\hline & t-ratio & 6.610 & 6.488 & 8.771 & 6.673 & 6.672 & 6.467 & 7.535 & 6.584 & 6.755 & 6.775 & 7.547 & 7.437 & 6.641 & 6.645 & 6.440 & 6.961 & 6.938 \\
\hline
\end{tabular}




\section{Table VI. Forecasting Accuracy of Alternative Fair Pricing Estimation Methods: Synthetic Funds with Different Stock Sizes}

This table reports the out-of-sample forecasting performance of alternative fair-pricing estimation methods for three synthetic funds with different stock. The methods investigated are: 1 . our proposed method which adjusts asset prices at the securities level using stepwise regressions; 2 . adjust asset price at the portfolio level using the S\&P500 futures index alone; 3. adjust asset price at the portfolio level using the Nikkei225 futures index alone; 4 . adjust asset price at the portfolio level using the S\&P500 and Nikkei225 futures indices combined; and 5. stale price without adjustment. Panel A displays the RMSE (in percent) of predicting asset prices at next-day Japan open. Panel B reports the $t$-statistic that our method 1 yields a lower RMSE than an alternative method. A $t$-statistic lower than $1.96(-2.58)$ indicates that our method outperforms an alternative method at the 5 (1) percent significance level in terms of forecasting accuracy. Both RMSEs and $t$-statistics are averages over 400 simulations.

\begin{tabular}{lccc}
\hline Stock Size & Large & Medium & Small \\
\hline \multicolumn{5}{r}{ Panel A. RMSE of Predicting Security Price at Next-Day Japan Open } \\
Method 1 & 0.586 & 0.619 & \\
Method 2 & 0.633 & 0.668 & 0.698 \\
Method 3 & 0.656 & 0.669 & 0.762 \\
Method 4 & 0.608 & 0.633 & 0.729 \\
Method 5 & 0.735 & 0.744 & 0.717 \\
Panel B. $t$-Statistic That Our Method 1 Yields a Lower RMSE Than an Alternative Method \\
Method 2 & & & \\
Method 3 & -5.451 & -5.397 & -6.263 \\
Method 4 & -6.647 & -6.431 & -4.382 \\
Method 5 & -3.411 & -2.320 & -2.581 \\
& -9.191 & -8.425 & -8.197 \\
\hline
\end{tabular}




\section{Table VII. Forecasting Accuracy of Alternative Fair Pricing Estimation Methods: Synthetic Funds with Different Turnover Ratios}

This table reports the out-of-sample forecasting performance of alternative fair-pricing estimation methods for seven synthetic funds with different turnover ratios. The methods investigated are: 1 . our proposed method which adjusts asset prices at the securities level using stepwise regressions; 2. adjust asset price at the portfolio level using the S\&P500 futures index alone; 3. adjust asset price at the portfolio level using the Nikkei225 futures index alone; 4. adjust asset price at the portfolio level using the S\&P500 and Nikkei225 futures indices combined; and 5. stale price without adjustment. Panel A displays the RMSE (in percent) of predicting asset prices at next-day Japan open. Panel B reports the $t$-statistic that our method 1 yields a lower RMSE than an alternative method. A $t$-statistic lower than $1.96(-2.58)$ indicates that our method outperforms an alternative method at the 5 (1) percent significance level in terms of forecasting accuracy. Both RMSEs and $t$-statistics are averages over 400 simulations.

\begin{tabular}{|c|c|c|c|c|c|c|c|}
\hline Turnover & 10 & 25 & 50 & 100 & 250 & 500 & 1000 \\
\hline \multicolumn{8}{|c|}{ Panel A. RMSE of Predicting Security Price at Next-Day Japan Open } \\
\hline Method 1 & 0.610 & 0.608 & 0.610 & 0.606 & 0.606 & 0.614 & 0.612 \\
\hline Method 2 & 0.664 & 0.663 & 0.663 & 0.658 & 0.656 & 0.663 & 0.662 \\
\hline Method 3 & 0.669 & 0.666 & 0.664 & 0.658 & 0.654 & 0.660 & 0.658 \\
\hline Method 4 & 0.627 & 0.625 & 0.626 & 0.622 & 0.622 & 0.629 & 0.628 \\
\hline Method 5 & 0.757 & 0.752 & 0.747 & 0.739 & 0.734 & 0.738 & 0.735 \\
\hline \multicolumn{8}{|c|}{ Panel B. $t$-Statistic That Our Method 1 Yields a Lower RMSE Than an Alternative Method } \\
\hline Method 2 & -5.845 & -5.881 & -5.863 & -5.867 & -5.828 & -5.731 & -5.718 \\
\hline Method 3 & -6.496 & -6.340 & -6.221 & -6.101 & -6.111 & -5.971 & -5.947 \\
\hline Method 4 & -2.582 & -2.581 & -2.547 & -2.567 & -2.627 & -2.515 & -2.549 \\
\hline Method 5 & -9.309 & -9.190 & -9.018 & -9.024 & -9.074 & -8.953 & -8.956 \\
\hline
\end{tabular}




\section{Table VIII. Forecasting Accuracy of Alternative Fair Pricing Estimation Methods: Synthetic Funds with Different Numbers of Stocks in Each Fund}

This table reports the out-of-sample forecasting performance of alternative fair-pricing estimation methods for five synthetic funds with different numbers of stocks in the funds. The methods investigated are: 1 . our proposed method which adjusts asset prices at the securities level using stepwise regressions; 2 . adjust asset price at the portfolio level using the S\&P500 futures index alone; 3. adjust asset price at the portfolio level using the Nikkei225 futures index alone; 4. adjust asset price at the portfolio level using the S\&P500 and Nikkei225 futures indices combined; and 5. stale price without adjustment. Panel A displays the RMSE (in percent) of predicting asset prices at next-day Japan open. Panel B reports the $t$-statistic that our method 1 yields a lower RMSE than an alternative method. A $t$-statistic lower than -1.96 (-2.58) indicates that our method outperforms an alternative method at the 5 (1) percent significance level in terms of forecasting accuracy. Both RMSEs and $t$-statistics are averages over 400 simulations.

\begin{tabular}{cccccc}
\hline $\begin{array}{c}\text { No of Stocks in } \\
\text { Fund }\end{array}$ & 25 & 50 & 100 & 250 & 500 \\
\hline \multicolumn{7}{c}{ Panel A. RMSE of Predicting Security Price at Next-Day Japan Open } \\
Method 1 & 0.719 & 0.640 & 0.582 & 0.548 & 0.534 \\
Method 2 & 0.763 & 0.689 & 0.636 & 0.605 & 0.593 \\
Method 3 & 0.763 & 0.689 & 0.636 & 0.605 & 0.594 \\
Method 4 & 0.733 & 0.655 & 0.598 & 0.566 & 0.552 \\
Method 5 & 0.833 & 0.767 & 0.720 & 0.693 & 0.683 \\
& & & & & \\
Panel B. $t$-Statistic That Our Method 1 Yields a Lower RMSE Than an Alternative Method & \\
Method 2 & -4.770 & -5.475 & -6.086 & -6.503 & -6.638 \\
Method 3 & -5.121 & -5.901 & -6.400 & -6.773 & -6.909 \\
Method 4 & -1.983 & -2.336 & -2.694 & -2.964 & -3.054 \\
Method 5 & -7.919 & -8.757 & -9.241 & -9.635 & -9.760 \\
\hline
\end{tabular}




\section{Table IX. Forecasting Accuracy of Alternative Fair Pricing Estimation Methods: Synthetic Funds with Different Book-to-Market Ratios}

This table reports the out-of-sample forecasting performance of alternative fair-pricing estimation methods for three synthetic funds with different book-to-market ratios. The methods investigated are: 1 . our proposed method which adjusts asset prices at the securities level using stepwise regressions; 2. adjust asset price at the portfolio level using the S\&P500 futures index alone; 3. adjust asset price at the portfolio level using the Nikkei225 futures index alone; 5. adjust asset price at the portfolio level using the S\&P500 and Nikkei225 futures indices combined; and 5. stale price without adjustment. Panel A displays the RMSE (in percent) of predicting asset prices at next-day Japan open. Panel B reports the $t$-statistic that our method 1 yields a lower RMSE than an alternative method. A $t$-statistic lower than -1.96 (-2.58) indicates that our method outperforms an alternative method at the 5 (1) percent significance level in terms of forecasting accuracy. Both RMSEs and $t$-statistics are averages over 400 simulations.

\begin{tabular}{cccc}
\hline Book-to-Market & High (Value) & Medium (Blend) & Low (Growth) \\
\hline \multicolumn{5}{c}{ Panel A. RMSE of Predicting Security Price at Next-Day Japan Open } \\
Method 1 & 0.598 & 0.579 & 0.639 \\
Method 2 & 0.649 & 0.628 & 0.699 \\
Method 3 & 0.631 & 0.622 & 0.713 \\
Method 4 & 0.614 & 0.592 & 0.660 \\
Method 5 & 0.690 & 0.696 & 0.813 \\
& & & \\
Panel B. $t$-Statistic That Our Method 1 Yields a Lower RMSE Than an Alternative Method \\
Method 2 & & & -6.243 \\
Method 3 & -5.723 & -5.556 & -6.537 \\
Method 4 & -5.604 & -6.038 & -3.031 \\
Method 5 & -2.629 & -2.151 & -9.342 \\
\hline
\end{tabular}




\section{Figure I. Time Frame in Regression Design}

Panel A draws the time frame in the regression of estimating fair price by Goetzmann et al. (2001), while Panel B displays the time frame in our regression setup. $R_{K, t}^{\text {stock }}$ is the percentage change in fund K's value in yen terms from Japan close on day (t-1) to Japan close on day $t, \mathrm{R}_{\mathrm{t}}^{\mathrm{FX}}$ is the percentage appreciation of the yen from U.S. close on day (t-1) to U.S. close on day $t, R_{M, t-1}$ is the return on index M from U.S. close on day (t-2) to U.S. close on day (t-1), $\mathrm{r}_{\mathrm{i}, \mathrm{t}}$ is the return in dollar terms on Japanese stock i from Japan close on day (t-1) to Japan open on day $t$, and $R_{F, t-1}$ is the return on factor $F$ from U.S. close on day (t-2) to U.S. close on day (t-1).

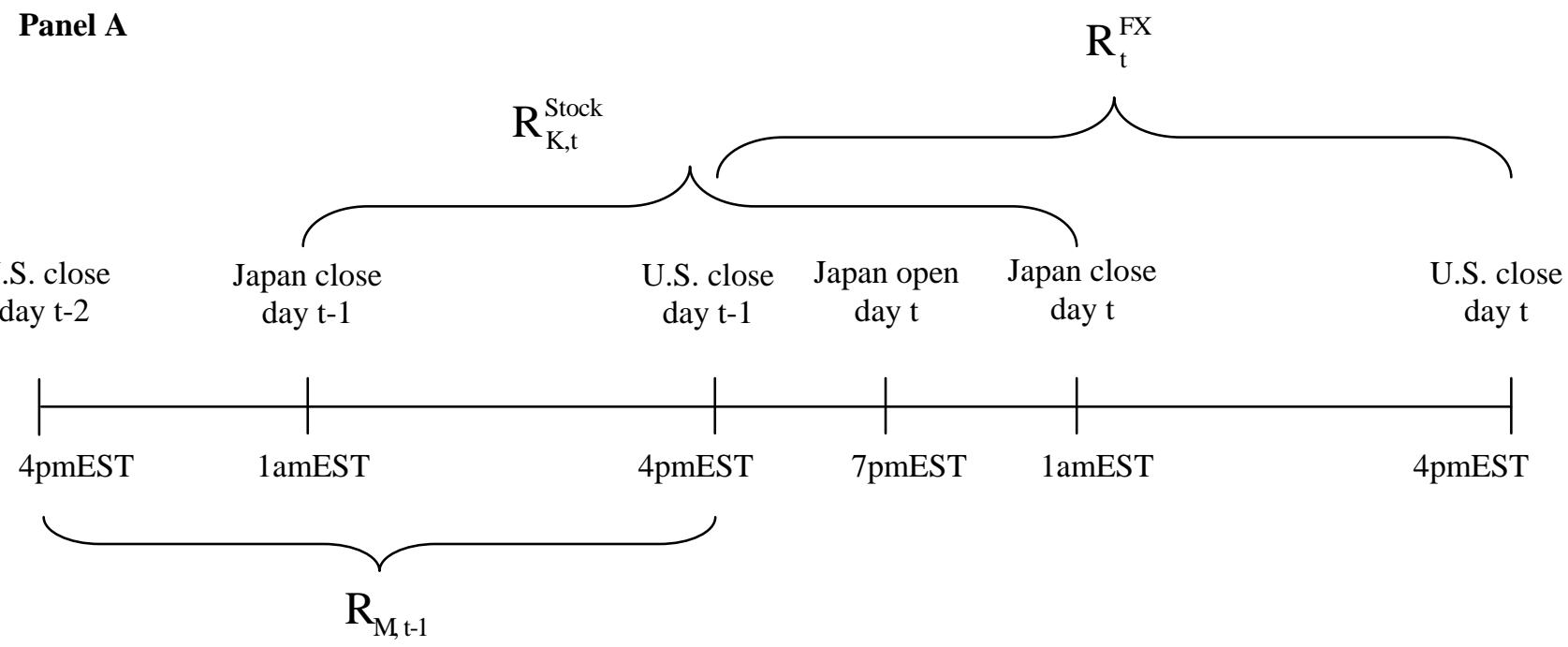

\section{Panel B}

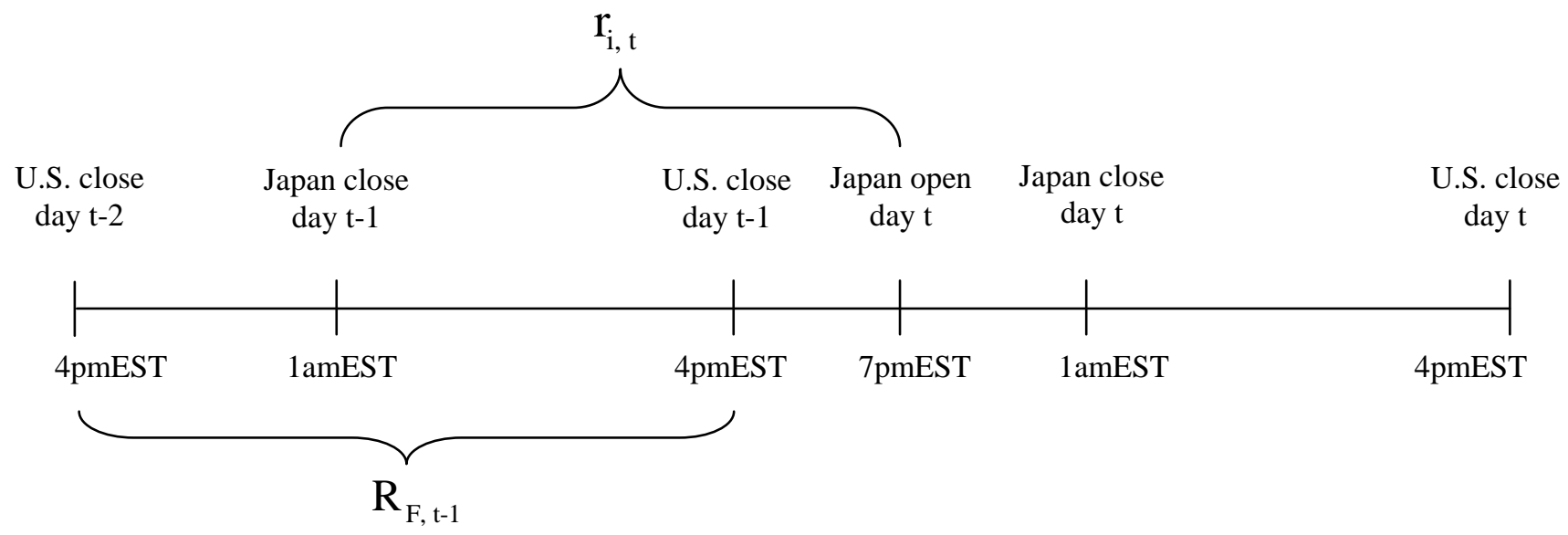




\section{Figure II. Performance Comparison Using Alternative Japanese Market Indices}

Panel A plots the out-of-sample RMSEs with respect to different regression window sizes for fair-pricing estimation using three alternative Japanese market indices alone: the Nikkei225 futures index, the Japan ETF, and the equallyweighted average ADR index. Panel B displays the out-of-sample RMSEs for fair-pricing estimation using the S\&P500 index combined with each of the three alternative Japanese market indices. The RSMEs are averages over 400 simulations.

\section{Panel A}

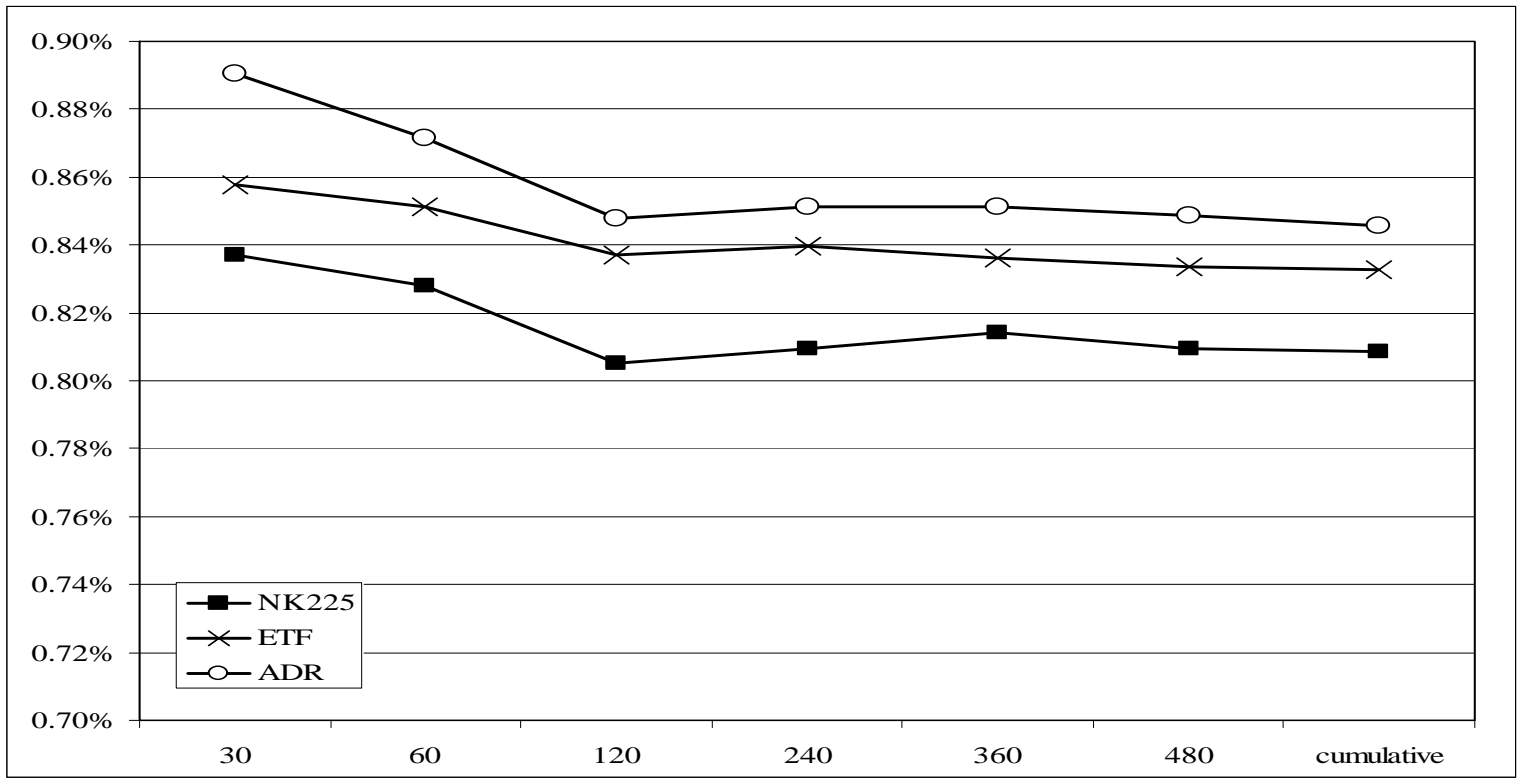

\section{Panel B}

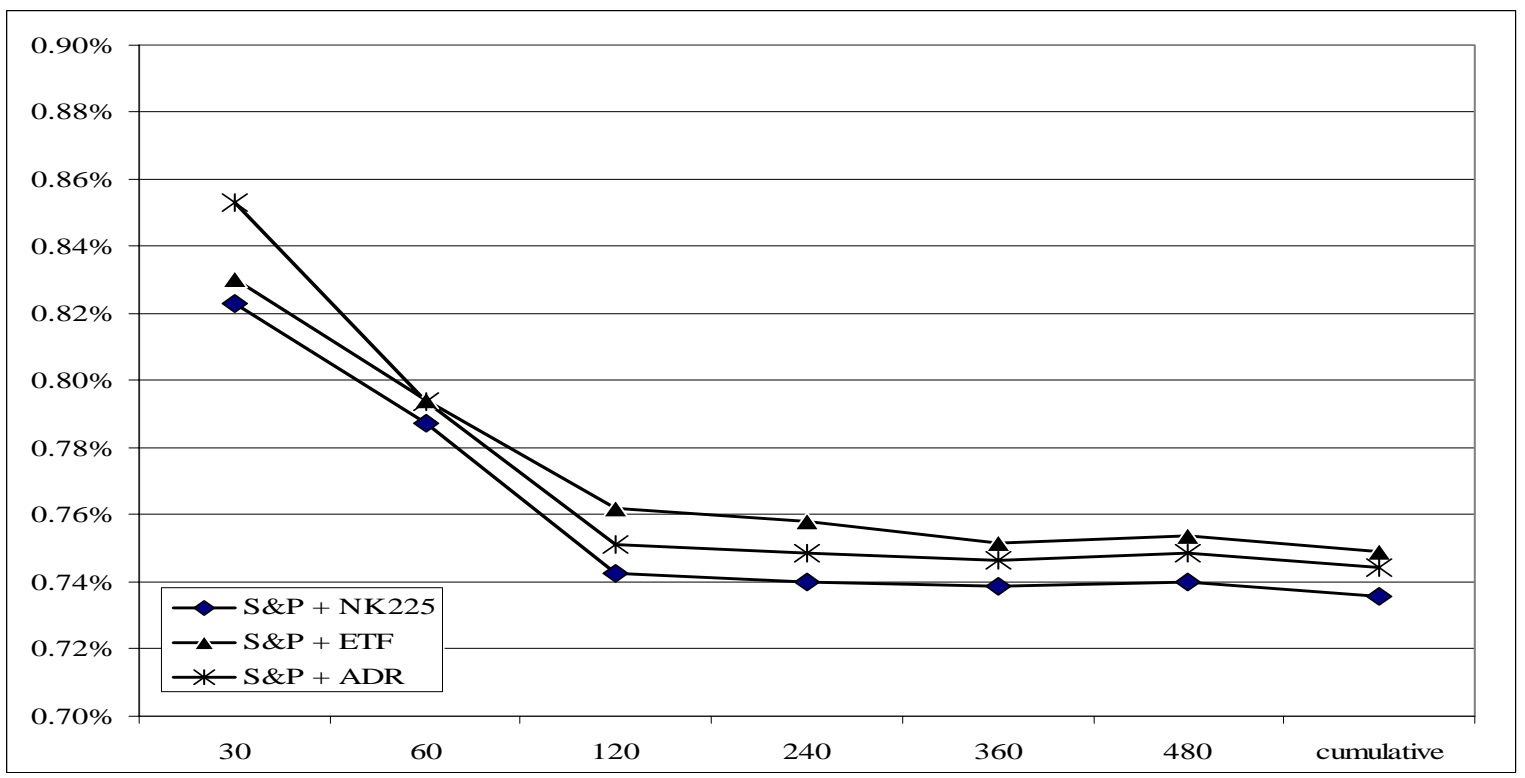




\section{Figure III. RMSE of Competing Methods with Respect to Regression Window Size}

This figure plots the out-of-sample RMSEs of competing fair-pricing estimation methods with respect to different regression window sizes. "S\&P" adjusts asset price at the portfolio level using the S\&P500 futures index alone; "NK225" adjusts asset price at the portfolio level using the Nikkei225 futures index alone; and "S\&P+NK225" adjust asset price at the portfolio level using the S\&P500 and Nikkei225 futures indices combined. The RMSEs are averages over 400 simulations.

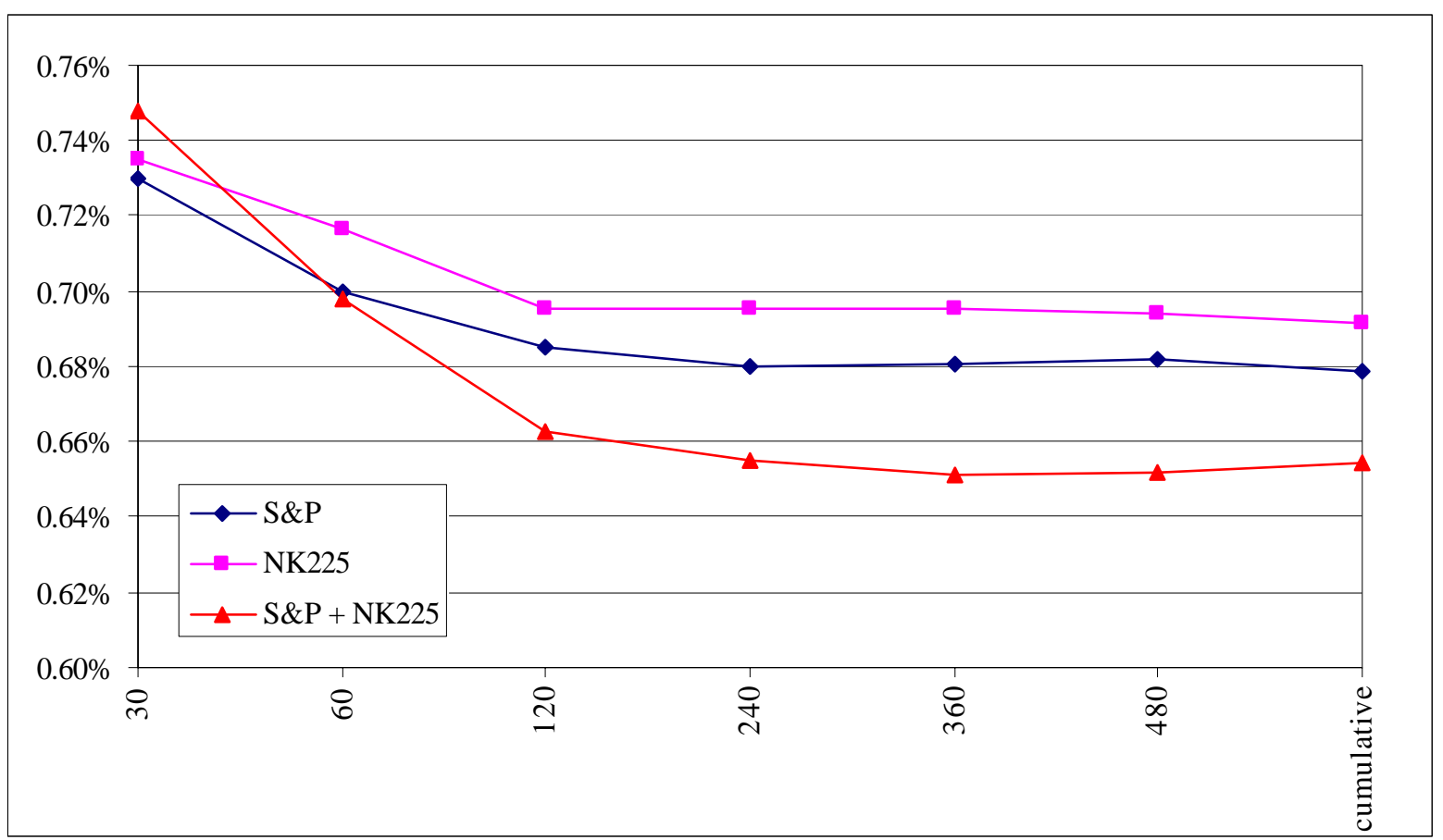




\section{Appendix}

This appendix describes the twelve industries, their SIC codes, and the 34 Japanese American Depository Receipts traded in the U.S. over the period from January 2, 1991 to December 31, 2001. The proportion of times each industry factor and ADR is selected into our empirical regression model is also reported.

Panel A. Industry Classification

\begin{tabular}{|c|c|c|c|}
\hline & Industry & SIC Code & Proportion \\
\hline 1. & Consumer NonDurables -- Food, Tobacco, Textiles, Apparel, Leather, Toys & 0100-0999, 2000-2399, 2700-2749, 2770-2799, 3100-3199, and 3940-3989. & $2.27 \%$ \\
\hline 2. & Consumer Durables -- Cars, TV's, Furniture, Household Appliances & $\begin{array}{l}\text { 2500-2519, 2590-2599, 3630-3659, 3710-3711, 3714-3714, 3716-3716, 3750-3751, 3792-3792, 3900- } \\
\text { 3939, and 3990-3999. }\end{array}$ & $1.77 \%$ \\
\hline 3. & Manufacturing -- Machinery, Trucks, Planes, Off Furn, Paper, Com Printing & $\begin{array}{l}\text { 2520-2589, 2600-2699, 2750-2769, 3000-3099, 3200-3569, 3580-3629, 3700-3709, 3712-3713, 3715- } \\
3715,3717-3749,3752-3791,3793-3799,3830-3839 \text {, and 3860-3899 }\end{array}$ & $2.59 \%$ \\
\hline 4. & Oil, Gas, and Coal Extraction and Products & $1200-1399$ and 2900-2999 & $1.91 \%$ \\
\hline 5. & Chemicals and Allied Products & $2800-2829$ and 2840-2899 & $1.72 \%$ \\
\hline 6. & Business Equipment -- Computers, Software, and Electronic Equipment & 3570-3579, 3660-3692, 3694-3699, 3810-3829, and 7370-7379 & $1.18 \%$ \\
\hline 7. & Telephone and Television Transmission & $4800-4899$ & $1.84 \%$ \\
\hline 8. & Utilities & $4900-4949$ & $3.85 \%$ \\
\hline 9. & Wholesale, Retail, and Some Services (Laundries, Repair Shops) & 5000-5999, 7200-7299, and 7600-7699 & $2.70 \%$ \\
\hline 10. & Healthcare, Medical Equipment, and Drugs & 2830-2839, 3693-3693, 3840-3859, and 8000-8099 & $1.08 \%$ \\
\hline 11. & Money Finance & $6000-6999$ & $1.74 \%$ \\
\hline & $\begin{array}{l}\text { Everything Else -- Mines, Constr, BldMt, Trans, Hotels, Bus Serv, } \\
\text { Entertainment }\end{array}$ & Others & $1.65 \%$ \\
\hline
\end{tabular}

Panel B. Japanese ADRs

\begin{tabular}{|c|c|c|c|c|c|c|c|c|}
\hline NO & ADR & Proportion & NO & ADR & Proportion & NO & ADR & Proportion \\
\hline 1 & ADVANTEST CORP & $0.05 \%$ & 13 & JAPAN AIRLINES SYS & $6.22 \%$ & 25 & ORIX CORP & $2.20 \%$ \\
\hline 2 & AMWAY JAPAN LTD & $3.02 \%$ & 14 & KIRIN BREWERY LTD & $4.38 \%$ & 26 & PIONEER CORP & $2.70 \%$ \\
\hline 3 & CANON INC & $3.54 \%$ & 15 & KUBOTA CORP & $8.38 \%$ & 27 & SANYO ELECTRIC CO LTD & $11.47 \%$ \\
\hline 4 & CRAYFISH CO LTD & $1.12 \%$ & 16 & KYOCERA CORP & $5.37 \%$ & 28 & SAWAKO CORP & $2.13 \%$ \\
\hline 5 & CROSSWAVE COMMUN INC & $0.38 \%$ & 17 & MAKITA CORP & $3.83 \%$ & 29 & SHISEIDO CO LTD & $5.71 \%$ \\
\hline 6 & CSK CORP & $10.52 \%$ & 18 & MATSUSHITA ELECTRIC & $3.23 \%$ & 30 & SONY CORP & $9.58 \%$ \\
\hline 7 & DAIEI INC & $4.31 \%$ & 19 & MILLEA HOLDINGS INC & $5.85 \%$ & 31 & TDK CORP & $4.28 \%$ \\
\hline 8 & FUJI PHOTO FILM & $3.32 \%$ & 20 & MITSUI \& CO LTD & $8.86 \%$ & 32 & TOYOTA MOTOR CORP & $3.58 \%$ \\
\hline 9 & HITACHI LTD & $12.43 \%$ & 21 & NEC CORP & $3.66 \%$ & 33 & TREND MICRO INC & $2.57 \%$ \\
\hline 10 & HONDA MOTOR LTD & $1.61 \%$ & 22 & NIDEC CORP & $0.03 \%$ & 34 & WACOAL CORP & $5.31 \%$ \\
\hline 11 & INTERNET INITIATIVE JP & $3.69 \%$ & 23 & NIPPON TELEGRPH \& TELE & $2.24 \%$ & & & \\
\hline 12 & ITO YOKADO CO LTD & $3.40 \%$ & 24 & NISSAN MOTOR CO LTD & $3.61 \%$ & & & \\
\hline
\end{tabular}

